\title{
Molecular characterization of atmospheric particulate organosulfates in three megacities at the middle and lower reaches of the Yangtze River
}

\author{
Xin Ke Wang ${ }^{1,2, *}$, Stéphanie Rossignol ${ }^{3, *}$, Ye Ma ${ }^{1,2}$, Lei Yao ${ }^{1,2}$, Ming Yi Wang ${ }^{1,2}$, Jian Min Chen ${ }^{1,2}$, \\ Christian George ${ }^{3}$, and Lin Wang ${ }^{1,2}$ \\ ${ }^{1}$ Shanghai Key Laboratory of Atmospheric Particle Pollution and Prevention (LAP ${ }^{3}$ ), Department of \\ Environmental Science \& Engineering, Fudan University, Shanghai 200433, China \\ ${ }^{2}$ Fudan Tyndall Centre, Fudan University, Shanghai 200433, China \\ ${ }^{3}$ Université de Lyon 1, Lyon, 69626, France; CNRS, UMR5256, IRCELYON, Institut de Recherches \\ sur la Catalyse et l'Environnement de Lyon, Villeurbanne, 69626, France \\ *These authors contributed equally to this work.
}

Correspondence to: Christian George (christian.george@ ircelyon.univ-lyon1.fr) and Lin Wang (lin_wang@fudan.edu.cn)

Received: 28 May 2015 - Published in Atmos. Chem. Phys. Discuss.: 10 August 2015

Revised: 31 January 2016 - Accepted: 12 February 2016 - Published: 26 February 2016

\begin{abstract}
PM}_{2.5}$ filter samples have been collected in three megacities at the middle and lower reaches of the Yangtze River: Wuhan (WH), Nanjing (NJ), and Shanghai (SH). The samples were analyzed using ultra-high-performance liquid chromatography (UHPLC) coupled with Orbitrap mass spectrometry (MS), which allowed for detection of about 200 formulas of particulate organosulfates (OSs), including dozens of formulas of nitrooxy-organosulfates, with various numbers of isomers for each tentatively determined formula at each location. The number of aliphatic OS formulas represented more than $78 \%$ of the detected OSs at the three locations, while aromatic OSs were much less numerous. OSs with two to four isomers accounted for about $50 \%$ of the total OSs on average in these megacity samples, and the percentage of OSs with six and more isomers in the WH sample was more significant than those in the SH and NJ samples. Additionally, the molecular formula, average molecular weight, and degrees of oxidation and unsaturation of tentatively assigned OSs were compared. The results indicate that the OSs between NJ and SH shared higher similarity, and the characteristics of OSs in SH varied diurnally and seasonally. OSs derived from isoprene, monoterpenes, and sesquiterpenes were abundant in samples from the three megacities and could be produced through both daytime photochemistry
\end{abstract}

and $\mathrm{NO}_{3}$ night-time chemistry. The reaction pathways leading to isoprene-derived OSs probably varied in those locations because of the different $\mathrm{NO}_{x}$ levels. In addition, a number of OSs that might be formed from polycyclic aromatic hydrocarbons were also detected, which underlies the importance of anthropogenic sources for this class of compounds.

\section{Introduction}

Atmospheric aerosols can scatter and absorb sunlight and provide cloud condensation nuclei. Hence, they have significant impacts on air quality and climate (Andreae and Crutzen, 1997; Hallquist et al., 2009). Aerosol particles contain a large fraction of toxic chemical substances and are harmful to human health (Magari et al., 2002; Ostro et al., 2007). Organosulfates (OSs) - i.e., sulfate esters and their derivatives formed from atmospheric heterogeneous and multiphase chemical reactions (Ma et al., 2012) - are a class of organic compounds that contribute to the total abundance of atmospheric aerosol particles (Tolocka and Turpin, 2012).

Surratt et al. (2007) were the first to identify isoprene- and $\alpha$-pinene-derived OSs in ambient aerosols in the southeast 
US using high-performance liquid chromatography coupled with electrospray mass spectrometry. Since then, tremendous progress has been made in the understanding of the formation mechanisms of OSs. Experimental studies show that isomeric isoprene epoxydiols (IEPOX) and methacrylic acid epoxide (MAE) are formed during the oxidation of isoprene under low- and high- $\mathrm{NO}_{x}$ conditions, respectively. Subsequent acid catalyzed-reactions of IEPOX and MAE in the presence of sulfates can lead to the formation of OSs (Darer et al., 2011; Lin et al., 2012c, 2013; Surratt et al., 2010; Paulot et al., 2009). OSs can be formed from reactions between $\alpha$-pinene and $\mathrm{OH}$ radicals, $\mathrm{NO}_{3}$ radicals, and $\mathrm{O}_{3}$ in the presence of sulfates, from $\beta$-pinene under high$\mathrm{NO}_{x}$ conditions, from ozonolysis and photochemical reactions of other monoterpenes ( $\alpha$-terpinene and $\gamma$-terpinene), and from sesquiterpene (i.e., $\beta$-caryophyllene) under acidic conditions (Surratt et al., 2008; Iinuma et al., 2007a, b; Chan et al., 2011). Sulfate and/or sulfite radical-induced oxidation reactions with unsaturated organic compounds including isoprene, methyl vinyl ketone, methacrolein, and $\alpha$-pinene in the aqueous phase represent another potential formation route of OSs (Szmigielski, 2015; Rudzinski et al., 2009; Noziere et al., 2010; Schindelka et al., 2013). In addition, both reactive uptake of carbonyl compounds on sulfuric acid or sulfates (Liggio et al., 2005) and hydrolysis reactions of organonitrates can lead to formation of OSs (Darer et al., 2011; Hu et al., 2011). Very recently, OSs and sulfonates were revealed to form from photo-oxidation of polycyclic aromatic hydrocarbons (PAHs) in the presence of sulfate seed (Riva et al., 2015b).

Identification and quantification of OSs in atmospheric particulate samples have been widely performed around the world (e.g., Kristensen and Glasius, 2011; Stone et al., 2009; Olson et al., 2011; Zhang et al., 2012). Many studies indicate that the total abundance of OSs varies from one region to another. OSs accounted for about $4 \%$ of the total organic mass in ambient aerosols over the southeast Pacific Ocean (Hawkins et al., 2010), whereas this contribution was estimated to be about $30 \%$ at the forested site of K-puszta in Hungary during summer (Surratt et al., 2008). The abundance of a given OS also shows clear variation between different sampling locations. The level of four aromatic OSs was estimated to be $234.4 \mathrm{pg} \mathrm{m}^{-3}$ in atmospheric $\mathrm{PM}_{2.5}$ in Pakistan, which were much more abundant than those in California $\left(8.9 \mathrm{pg} \mathrm{m}^{-3}\right.$ ) or Nepal $\left(3.9 \mathrm{pg} \mathrm{m}^{-3}\right.$ ) (Staudt et al., 2014).

In a given location, there are seasonal variations of OSs. For example, the $\alpha$-pinene-related nitrooxy-OSs were detected at high concentrations during the winter period, followed by autumn, spring, and summer at a rural background site in Hamme, Belgium (Kahnt et al., 2013). Ma et al. (2014) showed that the total mass concentration of 17 OSs was the highest in summer and lowest in winter, while no clear seasonal trend was observed in the mass concentration of benzyl sulfate (BS). However, BS showed the highest concentra- tion in winter and the lowest one in summer in Lahore, Pakistan (Kundu et al., 2013), which underlies the role of both regional constraints and meteorological conditions.

Recently, ultra-high-resolution mass spectrometry has been applied for tentative determination of the molecular formulas of OSs in atmospheric aerosols samples. Owing to the high mass resolution and mass accuracy of the ultra-highresolution mass spectrometer, the molecular formulas of analytes can be tentatively determined without the authentic standards required with low-resolution mass spectrometers. Lin et al. (2012a, b) studied aerosols sampled at a rural location of the Pearl River Delta Region in China and suggested that the arbitrary signal intensities of OSs obtained from the humic-like fraction are often the strongest in the electrospray ionization ultra-high-resolution mass spectra, and that the degrees of oxidation of OSs and nitrooxy OSs are quite high. Using a similar approach, O'Brien et al. (2014) showed that a significant portion of OSs was formed from biogenic precursors through the epoxide pathway in Bakersfield, CA, USA. In addition, by using a mixture of acetonitrile and toluene instead of a mixture of acetonitrile and water as the working solvent for nano-DESI ionization, Tao et al. (2014) tentatively determined many OSs with long aliphatic carbon chains and low degrees of oxidation and unsaturation, which were presumably formed from anthropogenic precursors emitted by cars in Shanghai (SH).

Although it has been accepted that OSs are an important component of ambient particulate matter, studies on their characteristics are rather sparse in China, especially in the Yangtze River region. Ma et al. (2014) identified and quantified 17 OSs in SH. As mentioned, Tao et al. (2014) compared OS characteristics such as the degrees of oxidation and saturation between samples from SH and Los Angeles. While SH has been a relative hotspot for OS characterization, the characteristics of OSs in the general Yangtze River region have yet to be elucidated. Wuhan (WH), Nanjing (NJ), and $\mathrm{SH}$ are three megacities at the middle and lower reaches of the Yangtze River with populations of over 10, 8, and 24 million, respectively (as of 2014). Tremendous amounts of energy are consumed owing to the large population and rapid economic development, leading to extensive emissions of anthropogenic pollutants including particulate matter, volatile organic compounds (VOCs), sulfur dioxide, and nitrogen oxides (Huang et al., 2011; Wang et al., 2013). At the same time, these three cities are located in the subtropical zone with high emissions of biogenic VOCs (Guenther et al., 1995). Hence, substantial amounts of OSs are likely to exist in $\mathrm{WH}, \mathrm{NJ}$, and $\mathrm{SH}$ aerosol particles. In this study, OSs, including nitrogen-containing OSs, were specifically searched for in $\mathrm{WH}, \mathrm{NJ}$, and $\mathrm{SH} \mathrm{PM}_{2.5}$ samples using ultrahigh-performance liquid chromatography (UHPLC) coupled to Orbitrap mass spectrometry (MS). Characteristics of OSs including the molecular formula, number of isomers, molecular weight, and the degrees of oxidation and unsaturation 


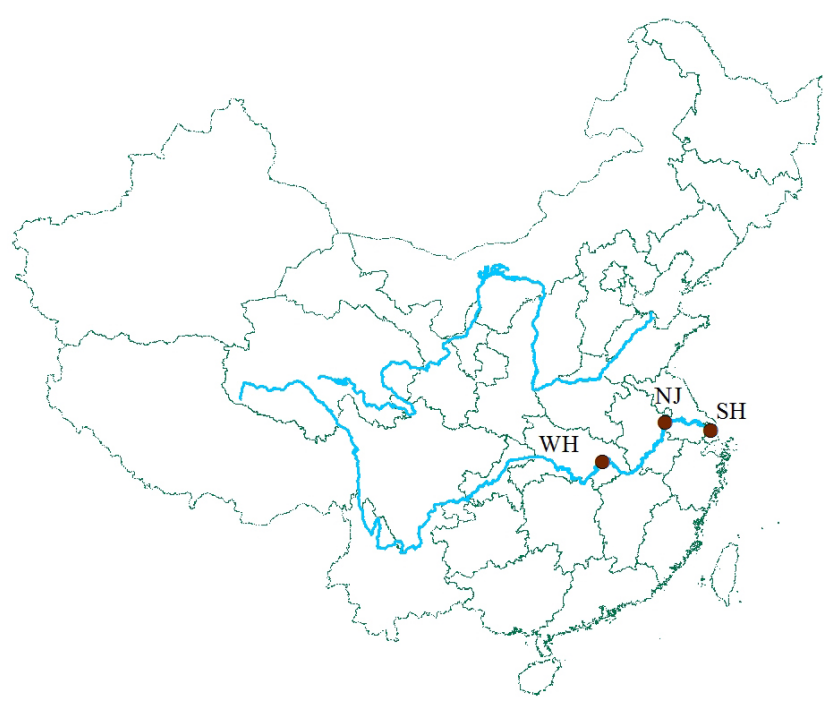

Figure 1. Locations of Wuhan (WH), Nanjing (NJ), and Shanghai (SH) in China.

were analyzed and compared. The potential precursors in the megacities are also discussed.

\section{Material and methods}

\subsection{Collection of $\mathbf{P M}_{2.5}$ samples}

Eight $\mathrm{PM}_{2.5}$ samples were collected at three locations: two in $\mathrm{WH}$, two in NJ, and four in SH, as shown in Fig. 1 and Table 1. Samples covering $24 \mathrm{~h}$ were collected in $\mathrm{WH}$ from 26 to 27 January (sample ID: WH winter, WHW) and from 15 to 16 June 2012 (sample ID: WH summer, WHS). The WH site was located on the rooftop of a dormitory building $\left(30^{\circ} 29^{\prime} \mathrm{N}, 114^{\circ} 24^{\prime} \mathrm{E}\right)$ that is about $20 \mathrm{~m}$ above ground at ZhongNan University of Economics and Law near a commercial street. NJ samples were collected from 29 to $30 \mathrm{Au}-$ gust 2012, for $12 \mathrm{~h}$ for each sample (samples ID: NJ summer daytime, NJSD; NJ summer nighttime, NJSN). The NJ site was located in the Chinese national meteorology observatory facility at the Nanjing University of Information Science and Technology $\left(32^{\circ} 12^{\prime} \mathrm{N}, 118^{\circ} 42^{\prime} \mathrm{E}\right)$, which is about $15 \mathrm{~km}$ north of the downtown area and about $2 \mathrm{~km}$ west of clusters of steel mills and petrochemical refinery facilities (Zheng et al., 2015).

$\mathrm{SH}$ samples were collected for $12 \mathrm{~h}$ from 17 to $18 \mathrm{Jan}$ uary 2013 (sample ID: SH winter daytime, SHWD; SH winter nighttime, SHWN), and 28 to 29 July 2013 (sample ID: SH summer daytime, SHSD; SH summer nighttime, SHSN). The SH site was located on the rooftop of a teaching building at Fudan University $\left(31^{\circ} 18^{\prime} \mathrm{N}, 121^{\circ} 30^{\prime} \mathrm{E}\right)$ about $20 \mathrm{~m}$ above ground with surrounding residential and commercial properties and a major highway to the south of the site (Xiao et al., 2015; Ma et al., 2014). Table S1 in the Supplement provides a comparison of air quality and meteorological conditions between the sampling days and the seasonal average in $\mathrm{SH}$.

$\mathrm{PM}_{2.5}$ was collected on $90 \mathrm{~mm}$ quartz-fiber filters (Whatman Company, UK) using a middle-flow impact aerosol sampler (Qingdao Hengyuan Tech Co., Ltd., HY-100) operating at $100 \mathrm{~L} \mathrm{~min}^{-1}$. All filters were prebaked at $500{ }^{\circ} \mathrm{C}$ for $5 \mathrm{~h}$ to remove residual organics before use. After sample collection, filters were wrapped in prebaked aluminum foil and stored at $-20^{\circ} \mathrm{C}$ before further analysis.

\subsection{Sample analysis}

One-fourth of each filter was put into an amber vial with $6 \mathrm{~mL}$ of methanol (Optima ${ }^{\circledR}$ LC/MS, Fischer Scientific, UK) and shaken for $20 \mathrm{~min}$ on an orbital shaker set to $1000 \mathrm{rpm}$. The extract was then filtered through a glass syringe on a $0.2 \mu \mathrm{m}$ PTFE membrane ( $13 \mathrm{~mm}$, Pall Corporation, USA). These two steps were performed twice, and the extracts of each filter were recombined and blown almost to dryness under a gentle stream of nitrogen. The extracts were then reconstituted in $1 \mathrm{~mL}$ of a $1: 1 v / v$ mixture of water $\left(\right.$ Optima ${ }^{\circledR}$ LC/MS, Fischer Scientific, USA) and acetonitrile (Optima ${ }^{\circledR}$ LC/MS, Fischer Scientific, USA). For the analysis, $100 \mu \mathrm{L}$ of the final reconstituted extract was diluted by adding $100 \mu \mathrm{L}$ of water. $5 \mu \mathrm{L}$ of these diluted solutions $(50 \mu \mathrm{L}$ in the case of the NJSD sample) were analyzed by UHPLC (Dionex 3000, Thermo Scientific, USA) coupled to a Q-Exactive Hybrid Quadrupole-Orbitrap mass spectrometer (Thermo scientific, USA). The efficiency and the repeatability on three replicates of the extraction protocol were checked using four standards: methyl sulfate, octyl sulfate, dodecyl sulfate, and camphor sulfonic acid. The results showed that their average extraction efficiencies were 71.4, 95.0, 97.7, and 94.0\%, respectively (Table S2). Analytical replicates were not considered because the final sample extract volume was quite low $(200 \mu \mathrm{L})$, and the remaining volume after the first injection was preferentially kept in case of specific analytical doubt rather than systematically injected.

Analytes were separated using a Waters Acquity HSS T3 column $(1.8 \mu \mathrm{m}, 100 \times 2.1 \mathrm{~mm})$ with mobile phases consisting of (A) $0.1 \%$ formic acid in water (Optima ${ }^{\circledR}$ LC/MS, Fischer Scientific, USA) and (B) $0.1 \%$ formic acid in acetonitrile (Optima ${ }^{\circledR}$ LC/MS, Fischer Scientific, USA). The concentration of eluent B was initially kept at $1 \%$ for $2 \mathrm{~min}$, then increased to $100 \%$ in $11 \mathrm{~min}$, kept at $100 \%$ for $2 \mathrm{~min}$, decreased to $1 \%$ in $0.1 \mathrm{~min}$, and kept at $1 \%$ for $6.9 \mathrm{~min}$. The Q-Exactive Hybrid Quadrupole-Orbitrap mass spectrometer was equipped with a heated electrospray ionization source. It was operated in the negative ion mode with a spray voltage of $-3.0 \mathrm{kV}$, a mass resolving power of 140000 at $\mathrm{m} / \mathrm{z} 200$, and a scanning range of $50-750 \mathrm{~m} / \mathrm{z}$. The Q-Exactive mass spectrometer was externally mass calibrated daily using a $2 \mathrm{mM}$ sodium acetate solution that provides a series of negative adduct ions in the range of $50-750 \mathrm{~m} / \mathrm{z}$. 
Table 1. Summary of sampling location, sampling time, molecular weight (MW), double bond equivalents (DBE), and elemental ratios (arithmetic mean \pm standard deviation) of tentatively assigned CHOS and CHONS.

\begin{tabular}{|c|c|c|c|c|c|c|c|c|c|c|c|}
\hline \multirow[t]{2}{*}{ Location } & \multirow[t]{2}{*}{ Sample ID } & \multirow[t]{2}{*}{ Sampling time } & \multirow{2}{*}{$\begin{array}{r}\text { Number of } \\
\text { formulas } \\
\text { CHOS/ } \\
\text { CHONS }\end{array}$} & \multicolumn{4}{|c|}{$\mathrm{CHOS}^{\mathrm{a}}$} & \multicolumn{4}{|c|}{$\mathrm{CHONS}^{\mathrm{b}}$} \\
\hline & & & & MW & DBE & $(o-3 s) / c^{\mathrm{c}}$ & $\mathrm{H} / \mathrm{C}^{\mathrm{d}}$ & MW & DBE & $(o-3 s-2 n) / \mathrm{c}^{\mathrm{e}}$ & $\mathrm{H} / \mathrm{C}$ \\
\hline \multirow[t]{2}{*}{ Wuhan } & WHW & $\begin{array}{l}\text { 9:00 a.m., } 26 \text { Jan- } \\
\text { 9:00 a.m., } 27 \text { Jan } 2012\end{array}$ & $149 / 43$ & $266.6 \pm 57.2$ & $2.56 \pm 2.60$ & $0.37 \pm 0.25$ & $1.68 \pm 0.44$ & $311.0 \pm 60.5$ & $3.61 \pm 2.57$ & $0.35 \pm 0.13$ & $1.58 \pm 0.46$ \\
\hline & WHS & $\begin{array}{l}8: 30 \text { a.m., } 15 \text { Jun- } \\
\text { 8:30 a.m., } 16 \text { Jun } 2012\end{array}$ & $213 / 55$ & $287.9 \pm 60.8$ & $2.16 \pm 1.64$ & $0.39 \pm 0.23$ & $1.75 \pm 0.36$ & $318.1 \pm 53.8$ & $2.98 \pm 1.52$ & $0.40 \pm 0.17$ & $1.69 \pm 0.34$ \\
\hline \multirow[t]{3}{*}{ Nanjing } & NJSD & $\begin{array}{l}\text { 7:30 a.m. }-7: 30 \text { p.m., } \\
29 \text { Aug } 2012\end{array}$ & $139 / 54$ & $288.9 \pm 67.9$ & $1.82 \pm 1.32$ & $0.39 \pm 0.25$ & $1.83 \pm 0.27$ & $313.6 \pm 48.2$ & $2.56 \pm 1.08$ & $0.44 \pm 0.21$ & $1.79 \pm 0.23$ \\
\hline & NJSN & $\begin{array}{l}\text { 7:30 p.m., } 29 \text { Aug- } \\
\text { 7:30 a.m., } 30 \text { Aug } 2012\end{array}$ & $160 / 72$ & $294.0 \pm 97.3$ & $3.21 \pm 3.84$ & $0.46 \pm 0.34$ & $1.65 \pm 0.45$ & $335.2 \pm 74.3$ & $3.46 \pm 2.30$ & $0.43 \pm 0.20$ & $1.66 \pm 0.37$ \\
\hline & NJSD + NJSN & Combination $^{\mathrm{f}}$ & $205 / 83$ & $304.8 \pm 93.5$ & $3.00 \pm 3.47$ & $0.43 \pm 0.32$ & $1.68 \pm 0.41$ & $332.5 \pm 70.7$ & $3.28 \pm 2.21$ & $0.44 \pm 0.21$ & $1.69 \pm 0.35$ \\
\hline \multirow[t]{6}{*}{ Shanghai } & SHWD & $\begin{array}{l}\text { 7:30 a.m. }-7: 30 \text { p.m., } \\
17 \text { Jan } 2013\end{array}$ & $125 / 32$ & $274.3 \pm 81.1$ & $2.38 \pm 2.56$ & $0.39 \pm 0.31$ & $1.72 \pm 0.46$ & $328.7 \pm 132.2$ & $4.22 \pm 3.95$ & $0.44 \pm 0.33$ & $1.53 \pm 0.57$ \\
\hline & SHWN & $\begin{array}{l}\text { 7:30 p.m., } 17 \text { Jan- } \\
\text { 7:30 a.m., } 18 \text { Jan } 2013\end{array}$ & $159 / 54$ & $270.0 \pm 71.1$ & $2.54 \pm 2.39$ & $0.40 \pm 0.29$ & $1.69 \pm 0.44$ & $303.9 \pm 51.9$ & $2.98 \pm 2.50$ & $0.38 \pm 0.17$ & $1.71 \pm 0.46$ \\
\hline & SHWD+SHWN & Combination ${ }^{\mathrm{f}}$ & $168 / 59$ & $277.2 \pm 71.2$ & $2.63 \pm 2.59$ & $0.40 \pm 0.29$ & $1.68 \pm 0.46$ & $325.8 \pm 92.0$ & $3.59 \pm 3.50$ & $0.42 \pm 0.27$ & $1.64 \pm 0.52$ \\
\hline & SHSD & $\begin{array}{l}\text { 8:00 a.m.-8:00 p.m., } \\
28 \text { Jul } 2013\end{array}$ & $165 / 40$ & $296.4 \pm 84.7$ & $2.76 \pm 2.66$ & $0.47 \pm 0.32$ & $1.68 \pm 0.42$ & $348.2 \pm 115.4$ & $4.03 \pm 3.48$ & $0.61 \pm 0.43$ & $1.55 \pm 0.52$ \\
\hline & SHSN & $\begin{array}{l}\text { 8:00 p.m., } 28 \text { Jul- } \\
\text { 8:00 a.m., } 29 \text { Jul } 2013\end{array}$ & $122 / 51$ & $278.1 \pm 73.9$ & $2.36 \pm 2.48$ & $0.48 \pm 0.29$ & $1.74 \pm 0.40$ & $319.2 \pm 73.0$ & $3.26 \pm 2.93$ & $0.45 \pm 0.22$ & $1.69 \pm 0.44$ \\
\hline & SHSD + SHSN & Combination $^{\mathrm{f}}$ & $168 / 58$ & $296.3 \pm 84.7$ & $2.77 \pm 2.65$ & $0.47 \pm 0.31$ & $1.68 \pm 0.42$ & $337.6 \pm 102.2$ & $3.52 \pm 3.04$ & $0.53 \pm 0.38$ & $1.64 \pm 0.47$ \\
\hline
\end{tabular}

a Molecules with $(o-4 s) / c<0$ were not included.

b Molecules with $(o-4 s-3 n) / c<0$ were not included.

c $(o-3 s) / c$ infers to the extent of oxidation for a CHOS molecule.

$\mathrm{d}_{\mathrm{H}} / \mathrm{C}$ refers to the ratio between hydrogen atom and carbon atom in a molecule.

$\mathrm{e}(o-3 s-2 n) / c$ refers to the extent of oxidation for a CHONS molecule.

${ }^{\mathrm{f}}$ Combination of two samples for a comparison purpose.

\subsection{Data processing}

The obtained chromatograms were analyzed with Progenesis QI software (V1.0, Waters Corporation) by assuming that the extracted ions in the range of $50-750 \mathrm{~m} / z$ [M-H] were formed from loss of a proton from the analytes. In contrast to direct infusion, the LC separation provides meaningful help in distinguishing quasi-molecular ions and potential in-source formed adducts for the same chromatographic retention time. A molecular formula calculator was then used to mathematically assign all possible formulas for an extracted quasi-molecular ion with a mass tolerance of $\pm 2 \mathrm{ppm}$. These molecular formulas can be expressed as $\mathrm{C}_{c} \mathrm{H}_{h} \mathrm{O}_{o} \mathrm{~N}_{n} \mathrm{~S}_{s}$, where $c$ is the number of carbon atoms in the range of $1-40$, $h$ is the number of hydrogen atoms in the range of 2-80, $o$ is the number of oxygen atoms in the range of $0-40, n$ is the number of nitrogen atoms in the range of $0-3$, and $s$ is the number of sulfur atoms in the range of $0-2$. Formulas were further constrained by setting $\mathrm{H} / \mathrm{C}, \mathrm{O} / \mathrm{C}, \mathrm{N} / \mathrm{C}, \mathrm{S} / \mathrm{C}$, and double bond equivalent to carbon number ratios (DBE / C) in the ranges of $0.3-3.0,0-3,0-0.5,0-0.2$, and $0-1$, respectively. This was done to ensure that the retrieved molecular formula do exist in nature (Fuller et al., 2012; Lin et al., 2012a, b).

The number of ions with more than one reasonable formula within $2 \mathrm{ppm}$ mass tolerance accounted only for $1.5 \%$ of the total number of tentatively determined ions, and the formulas with the best accuracy are listed in Table S3. The peak intensities of isotopically substituted ions were constrained by their low abundance and were hence not system- atically checked. Compounds that satisfy these criteria and present a number of oxygen atoms greater than or equal to $4 s+3 n(4 s+3 n \leq o)$ were tentatively regarded as OSs or nitrooxy OSs. However, tandem MS experiments were not conducted on the S- and $\mathrm{N}$-containing ions detected in these eight ambient samples. Therefore, other S- and N-containing compounds, such as sulfonates or compounds bearing nitro groups, may also be involved (e.g., Riva et al., 2015b; El Haddad et al., 2013) due to the lack of using tandem MS experiments to provide insights into the structures of these ions.

In this study, the abundance of an OS refers to the area of its chromatographic peak, and the number of isomers for an OS is based on the number of chromatographic peaks observed for given $m / z$ values. Note that the obtained number of isomers may vary significantly when the separation method is further optimized. Then, the arbitrary abundances of all isomers for a given $m / z$ value are added up. The arbitrary abundance of the most abundant OS or nitrooxy-OS in each sample is defined as $100 \%$, and only OSs and nitrooxyOSs with an arbitrary abundance larger than $0.5 \%$ of the most abundant one in the same sample are presented. The signal-to-noise ratios of the least abundant OSs in each sample are greater than 10 with a noise level of ca. $1 \times 10^{4}$ arbitrary units. Note that the arbitrary abundance of a given OS does not directly reflect its concentration compared to others in the same sample because the ionization efficiency is compound and solvent specific in electrospray ionization. Also, similar ionization efficiency is assumed for a given OS in dif- 
ferent samples as similar retention times are observed and as UHPLC separation resolves most of the matrix components.

Blank filters were processed and analyzed in an identical way, and blank correction was made as follows. The presence of targeted quasi-molecular ions in the blanks was systematically verified, and if a chromatographic peak was indeed detected, then it was retained (i.e., considered as real) only if the sample-to-blank ratio of the peak area was greater than 10 , with the blank value being subtracted prior to further processing. The DBE value of a molecule reflects the degree of its unsaturation. The DBE value is usually calculated as

$\mathrm{DBE}=\frac{2 c+2+n-h}{2}$.

Not taking into account the two double bonds involved in each sulfate group, the DBE values of OSs calculated by Eq. (1) represent the unsaturation degree of the side carbon chain (eventually bearing oxygen and nitrogen atoms). In addition, one can note that this equation adds one DBE unit for each nitrate group. Molecular formulas with DBE $<0$ and formulas that disobey the nitrogen rule were discarded. The difference between the DBE value and the number of $\mathrm{N}$ atoms (DBE- $\mathrm{n}$ ) is the most conservative criterion to determine whether a compound is aliphatic: the number of OSs with (DBE-n) $<4$ can be regarded as the minimum number of aliphatic OSs (Lin et al., 2012b).

Both DBE / C and the aromaticity index (AI) could be used as criteria to determine whether a compound contains aromatic rings with thresholds of DBE / C > 0.67 and $\mathrm{AI}>0.5$, respectively. However, $\mathrm{AI}$ is more conservative (Koch and Dittmar, 2006). The value of AI can be calculated according to

$\mathrm{AI}=\frac{\mathrm{DBE}_{\mathrm{AI}}}{\mathrm{C}_{\mathrm{AI}}}=\frac{1+c-o-s-(0.5 \mathrm{~h})}{c-o-s-n}$,

where $\mathrm{DBE}_{\mathrm{AI}}$ represents the sum of the minimum number of $\mathrm{C}=\mathrm{C}$ double bonds and the number of rings in a formula containing heteroatoms, and $\mathrm{C}_{\mathrm{AI}}$ represents the difference between the number of carbon and the number of potential double bonds caused by heteroatoms. If $\mathrm{DBE}_{\mathrm{AI}} \leq 0$ or $\mathrm{C}_{\mathrm{AI}} \leq 0$, then $\mathrm{AI}$ is defined to be zero. In contrast, $\mathrm{AI}>0.5$ and $\mathrm{AI} \geq 0.67$ indicate the existence of aromatic and fused aromatic ring structures in a compound, respectively (Koch and Dittmar, 2006).

In the Kendrick mass defect diagram (KMD diagram), $\mathrm{CH}_{2}(14.00000)$ was chosen as a base unit. The Kendrick mass $\left(\mathrm{KM}_{\mathrm{CH}_{2}}\right)$ and the Kendrick mass defect $\left(\mathrm{KMD}_{\mathrm{CH}_{2}}\right)$ can be determined by Eqs. (3) and (4), respectively:

$\mathrm{KM}_{\mathrm{CH}_{2}}=$ Observed Mass $\times\left(\frac{14.00000}{14.01565}\right)$

$\mathrm{KMD}_{\mathrm{CH}_{2}}=$ Nominal Mass $-\mathrm{KM}_{\mathrm{CH}_{2}}$,

where "Observed Mass" is the mass measured by the mass spectrometer, and "Nominal Mass" is the rounded integer mass of a compound.

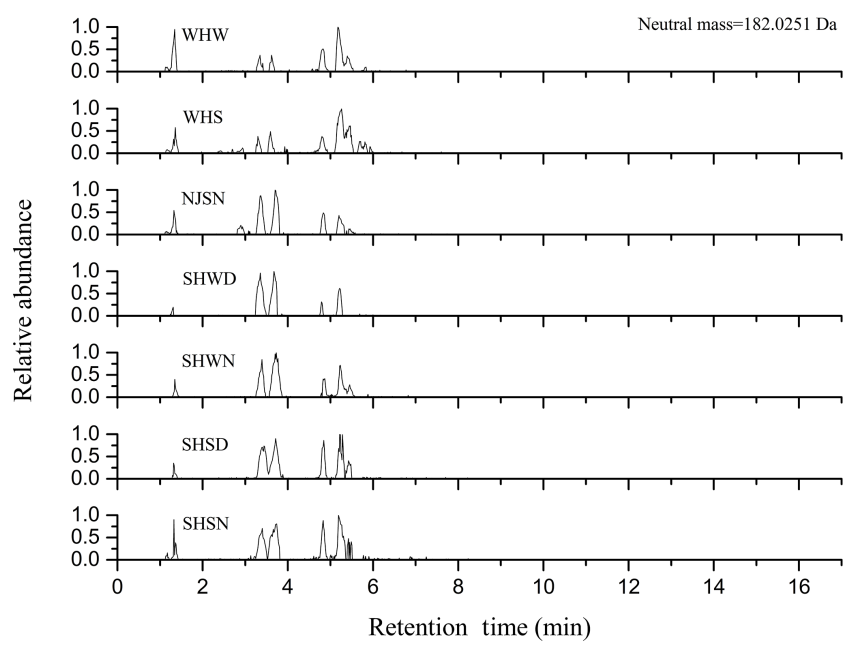

Figure 2. LC chromatograms of tentatively determined $\mathrm{C}_{5} \mathrm{H}_{10} \mathrm{O}_{5} \mathrm{~S}_{1}$ (potentially from isoprene). A chromatogram for the NJSD sample is not included because a large amount of sample injection led to corruption of peaks and hence inaccurate retention times and worse peak resolution.

\section{Results and discussion}

\subsection{Isomers}

UHPLC separation was applied prior to MS analysis for detection of potential isomers hidden behind a given $\mathrm{m} / z$ value and to provide another dimension of the ambient aerosol composition complexity. As an example, Fig. 2 shows the extracted ion chromatograms for $\mathrm{C}_{5} \mathrm{H}_{10} \mathrm{O}_{5} \mathrm{~S}$. An OS with this molecular formula has recently been identified in laboratorygenerated secondary organic aerosols either from the ozonolysis of isoprene in the presence of sulfate aerosols or from the transformations of isoprene coupled with S(IV)-autoxidation in the aqueous-phase, but only one and two isomers were detected by UPLC high-resolution mass spectrometers, respectively (Riva et al., 2015a; Szmigielski, 2015). From our ambient samples, 11 isomers were detected in total, with varying numbers of isomers in each sample (see Fig. 2 and Table S3). On the other hand, only two isomers were detected in the ambient $\mathrm{PM}_{2.5}$ samples from the Diabla Gora rural site (Szmigielski, 2015). The reason for this difference in the number of isomers among these studies might arise from the different chromatographic conditions and additional precursors, including different terpenes. In addition, it is difficult to assign which isomers have been detected by Riva et al. (2015a) and Szmigielski (2015) due to different chromatographic conditions and detectors.

Additional extracted ion chromatograms are presented in the Supplement for $\mathrm{C}_{5} \mathrm{H}_{12} \mathrm{O}_{7} \mathrm{~S}_{1}, \mathrm{C}_{10} \mathrm{H}_{17} \mathrm{O}_{7} \mathrm{~N}_{1} \mathrm{~S}_{1}$, and $\mathrm{C}_{16} \mathrm{H}_{32} \mathrm{O}_{6} \mathrm{~S}_{1}$ (Fig. $\mathrm{S} 1$ in the Supplement). Two and four isomers were detected for $\mathrm{C}_{5} \mathrm{H}_{12} \mathrm{O}_{7} \mathrm{~S}_{1}$ and $\mathrm{C}_{10} \mathrm{H}_{17} \mathrm{O}_{7} \mathrm{~N}_{1} \mathrm{~S}_{1}$, respectively, whereas Surratt et al. (2008) detected one and six 
isomers for these OSs, also from ambient samples. A thorough analysis of UHPLC-Orbitrap MS data leads to the tentative determination of more than $100 \mathrm{CHOS}$ formulas and dozens of CHONS formulas, with various numbers of isomers in each sample. The full list of the neutral mass, molecular formula, number of isomers, retention times, and potential precursors for these assigned OSs is tabulated in Table S3. Having access to the isomeric pattern of significant OSs could be very helpful in the future for identifying possible OS sources. Thus, Table S3 provides one of the first data sets of OS isomers in ambient samples.

The full mass spectra in summer samples from the three megacities, including all tentatively assigned OSs, have been reconstructed to present the samples' general characteristics. In Fig. 3, the $X$ axis corresponds to the neutral molecular weights of detected OSs, the $Y$ axis represents their arbitrary abundances, and the number of isomers per detected mass is color-coded. Comparison of the reconstructed mass spectra shows that the number of OSs with an identical formula and the same number of isomers that could be observed in all three megacities accounted for only $17.6 \%$ of all the tentatively assigned OS molecular formulas. Between WHS and NJSN, the proportion of OSs sharing identical formulas reached $50.3 \%$, but only $27.9 \%$ also possessed the same number of isomers. Quite similarly, between NJSN and SHSD + SHSN, the proportion of OSs sharing identical formulas reached $62.8 \%$, but only $39.4 \%$ also had the same number of isomers. Between WHS and SHSD + SHSN, this proportion reached $51.5 \%$, with only $32.3 \%$ having the same number of isomers. Therefore, one can consider that the samples from NJ and SH showed greater similarity, especially from their isomeric patterns. This observation is in agreement with the proximity of the two megacities compared to the more distant megacity of WH.

As shown in Fig. 3, OSs with two to four isomers accounted for about $50 \%$ of the total detected OSs. Those with more than six isomers accounted for the largest proportion, and OSs with one isomer were insignificant in WH. In contrast, in $\mathrm{SH}$ and NJ, OSs with one isomer only were preponderant, while those with more than six isomers were much less numerous. Clearly, the isomeric pattern differs significantly in WH compared to the other two megacities, probably due to the diversity in precursors and/or oxidation mechanism.

\subsection{Tentative assignment and potential precursors of major OSs}

The gaseous precursors of many OSs in Fig. 3 can be tentatively assigned, since identical formulas of OSs have been observed in chamber studies. In Fig. 3, OSs with strong arbitrary intensities have been labeled with a letter as follows: $\mathrm{A}: \mathrm{C}_{5} \mathrm{H}_{8} \mathrm{O}_{3} \mathrm{SO}_{4} ; \mathrm{B}: \mathrm{C}_{5} \mathrm{H}_{12} \mathrm{O}_{3} \mathrm{SO}_{4} ; \mathrm{C}: \mathrm{C}_{6} \mathrm{H}_{10} \mathrm{O}_{3} \mathrm{SO}_{4}$; D: $\mathrm{C}_{7} \mathrm{H}_{12} \mathrm{O}_{3} \mathrm{SO}_{4} ; \mathrm{E}: \mathrm{C}_{9} \mathrm{H}_{18} \mathrm{O}_{2} \mathrm{SO}_{4} ; \mathrm{F}: \mathrm{C}_{5} \mathrm{H}_{11} \mathrm{O}_{2} \mathrm{NO}_{3} \mathrm{SO}_{4}$; G: $\mathrm{C}_{9} \mathrm{H}_{16} \mathrm{O}_{3} \mathrm{SO}_{4} ; \mathrm{H}: \mathrm{C}_{10} \mathrm{H}_{17} \mathrm{NO}_{3} \mathrm{SO}_{4} ; \mathrm{I}: \mathrm{C}_{5} \mathrm{H}_{10} \mathrm{O}_{1}\left(\mathrm{NO}_{3}\right)_{2} \mathrm{SO}_{4}$;
J: $\mathrm{C}_{16} \mathrm{H}_{32} \mathrm{O}_{2} \mathrm{SO}_{4}$; and $\mathrm{K}: \mathrm{C}_{15} \mathrm{H}_{25} \mathrm{NO}_{3} \mathrm{SO}_{4}$. Among these OSs, A, C, D, and G are a series of homologues, and so are $\mathrm{E}$ and $\mathrm{J}$. A, B, F, and I could be derived from isoprene, whereas $\mathrm{D}$ and $\mathrm{G}$ could be derived from limonene, $\mathrm{C}$ from 3-Z-hexenal, $\mathrm{K}$ from $\beta$-caryophyllene, and $\mathrm{H}$ from various monoterpenes (i.e., $\alpha$-pinene, $\beta$-pinene, $\alpha$-terpinene and terpinolene) (Chan et al., 2011; Shalamzari et al., 2014; Surratt et al., 2008; Gomez-Gonzalez et al., 2008). E and J were characterized by high molecular weights and degrees of saturation, presumably being long-chain aliphatic OSs. In general, many abundant OSs could be derived from isoprene, monoterpenes, and sesquiterpenes in these three megacities.

The relative abundance of $\mathbf{J}$ was the highest in $\mathrm{WH}$ but much lower in the NJSN and SHSD + SHSN samples. H was the highest in the SHSD + SHSN samples, while I was the most abundant in the NJSN sample. It is doubtless that I bears two nitrate groups (two nitrogen atoms in its formula that fulfill the $4 s+3 n \leq o$ rule) and is the most abundant in the NJSN sample, likely due to active $\mathrm{NO}_{3}$ radical chemistry at night. $\mathrm{F}$ and $\mathrm{K}$, which bear one nitrate group, were also quite abundant in the NJSN sample, underlying the role of $\mathrm{NO}_{3}$ chemistry at night. The isomer ratios vary from sample to sample and therefore certainly carry information about their origin. These ratios and possible VOC precursors for these most abundant OSs are summarized in Table S4.

\subsection{Comparison of OS characteristics}

Table 1 summarizes the average characteristics (molecular weight, DBE, and elemental ratios) of tentatively assigned CHOS and CHONS compounds. These CHOS and CHONS compounds were here tentatively regarded as organosulfates and nitrooxy-organosulfates respectively, but other S- and Ncontaining functional groups could be involved as well in a small amount (Lin et al., 2012b). In addition, $(o-3 s) / c$ (Tao et al., 2014) and $(o-3 s-2 n) / c$ have been calculated to illustrate the number of oxygen-containing functional groups per carbon atom. These two values are derived from the fact that each sulfate and nitrate group respectively contains three and two oxygen atoms more than do common oxygen-containing groups, such as a hydroxyl or a carbonyl moiety. $(o-3 s) / c$ and $(o-3 s-2 n) / c$ can therefore be regarded as measures of the degree of oxidation of CHOS and CHONS compounds, respectively.

The average molecular weight and DBE value of CHONS species were generally larger than those of CHOS analogues, because CHONS contains one or two more nitrate groups (the presence of one nitrate group adding one DBE unit). Measurement of the $\mathrm{O} / \mathrm{C}$ ratio of OSs in Bakersfield (CA, USA) indicated that the degree of oxidation of CHONS was larger than that of CHOS throughout the day (O'Brien et al., 2014). A similar trend has been observed for $\mathrm{CHONS}_{1}$ and $\mathrm{CHOS}_{1}$ in $\mathrm{SH}$ and Los Angeles aerosol samples but using the $(o-3) / c$ ratio to measure the degree of oxidation (Tao et al., 2014). In this study, however, the average degree of oxidation 


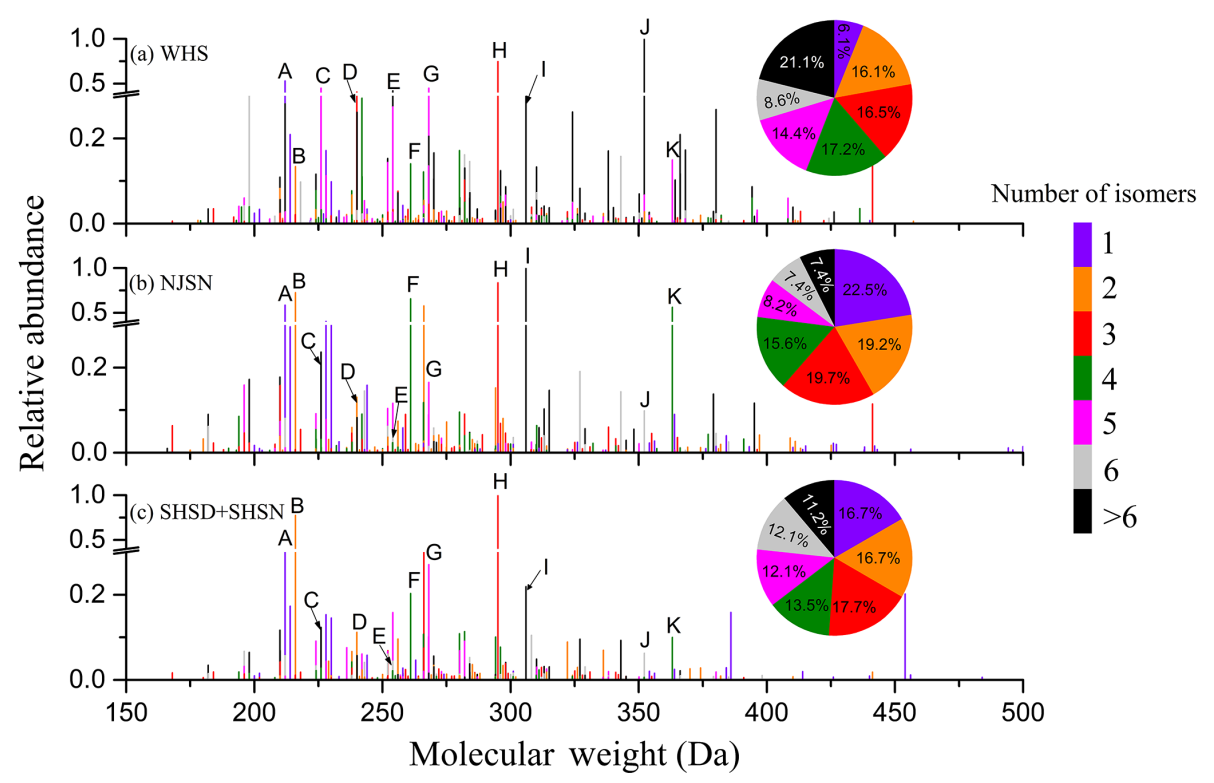

Figure 3. Mass spectra of detected CHOS and CHONS reconstructed from extracted ion chromatograms (UHPLC-Orbitrap MS analysis, negative ionization mode). $X$ axis corresponds to the molecular weight (Da) of the identified species. The number of isomers for a given formula is marked by colors. A, neutral mass $=211.9993 \mathrm{Da}, \mathrm{C}_{5} \mathrm{H}_{8} \mathrm{O}_{7} \mathrm{~S}_{1} ; \mathrm{B}$, neutral mass $=216.0306 \mathrm{Da}_{5} \mathrm{C}_{5} \mathrm{H}_{12} \mathrm{O}_{7} \mathrm{~S}_{1} ; \mathrm{C}$, neutral mass $=226.0150 \mathrm{Da}, \mathrm{C}_{6} \mathrm{H}_{10} \mathrm{O}_{7} \mathrm{~S}_{1} ; \mathrm{D}$, neutral mass $=240.0307 \mathrm{Da}, \mathrm{C}_{7} \mathrm{H}_{12} \mathrm{O}_{7} \mathrm{~S}_{1} ; \mathrm{E}$, neutral mass $=254.0827 \mathrm{Da}_{2} \mathrm{C}_{9} \mathrm{H}_{18} \mathrm{O}_{6} \mathrm{~S}_{1} ; \mathrm{F}$, neutral mass $=261.0157 \mathrm{Da}, \mathrm{C}_{5} \mathrm{H}_{11} \mathrm{O}_{9} \mathrm{~N}_{1} \mathrm{~S}_{1} ; \mathrm{G}$, neutral mass $=268.0620 \mathrm{Da}, \mathrm{C}_{9} \mathrm{H}_{16} \mathrm{O}_{7} \mathrm{~S}_{1} ; \mathrm{H}$, neutral mass $=295.0729 \mathrm{Da}_{1} \mathrm{C}_{10} \mathrm{H}_{17} \mathrm{O}_{7} \mathrm{~N}_{1} \mathrm{~S}_{1} ; \mathrm{I}$, neu$_{-}$ tral mass $=306.0007 \mathrm{Da}, \mathrm{C}_{5} \mathrm{H}_{10} \mathrm{O}_{11} \mathrm{~N}_{2} \mathrm{~S}_{1}$; J, neutral mass $=352.1922 \mathrm{Da}, \mathrm{C}_{16} \mathrm{H}_{32} \mathrm{O}_{6} \mathrm{~S}_{1} ; \mathrm{K}$, neutral mass $=363.1356 \mathrm{Da}_{15} \mathrm{C}_{15} \mathrm{H}_{25} \mathrm{O}_{7} \mathrm{~N}_{1} \mathrm{~S}_{1}$.

of CHONS was only slightly larger than that of CHOS during the daytime and slightly smaller at night. The use of the $(o-3 s) / c$ and $(o-3 s-2 n) / c$ ratios to evaluate the degrees of oxidation of the CHOS and CHONS carbon chain, respectively, allows for precise comparison of the oxidation states of these two classes of compounds. The values of the oxidation states for OSs and nitrooxy-OSs on a same sample ( 0.01 to 0.14 units of difference) suggest that the presence of the sulfate and/or nitrate groups is not determinant.

The OSs with (DBE-n) $<4$ accounted for 86.2, 78.5, and $78.3 \%$ of total OSs in $\mathrm{WH}, \mathrm{NJ}$, and $\mathrm{SH}$, respectively, suggesting tentatively assigned OSs were mainly aliphatic OSs. Also, the number of OSs with (DBE-n) $\geq 4$ can be regarded as the maximum number of aromatic OSs. This value appears to be slightly higher in SH (21.7\%) and NJ (21.5\%) compared to WH (13.8\%), possibly indicating a slightly more significant anthropogenic influence for the first two cities.

The number of OSs with DBE / C >0.67 accounted for $2.2,5.2$, and $7.1 \%$ of total OSs, and their abundance accounted for $0.6,1.4$, and $8.0 \%$ of total abundances of OSs in WHS, NJSD + NJSN, and SHSD + SHSN, respectively. Only a few aromatic OSs with AI $>0.5$ were detected, but it could be due to the fact that this value takes into account carbon-bounded $\mathrm{S}$ and $\mathrm{N}$ but not sulfate and nitrate groups (and the related oxygen atoms), underestimating the aromatic ring content. BS and its analogues were nevertheless detected in most of the samples of the three megacities.
Figure 4 shows the $\mathrm{CH}_{2}$-Kendrick diagrams and Van Krevelen (VK) diagrams for CHOS species for the WHS, NJSD + NJSN, and SHSD + SHSN samples, respectively, and the variation in DBE is color-coded. In the $\mathrm{CH}_{2}$ Kendrick diagram, compounds in a homologue series of compounds with identical $\mathrm{KMD}_{\mathrm{CH}_{2}}$ values form a horizontal line. The molecular formulas of the homologue series 1 and 2, which have $\mathrm{DBE}$ values equal to zero, can be written as $\mathrm{C}_{n} \mathrm{H}_{2 n+2} \mathrm{SO}_{4}$ and $\mathrm{C}_{n} \mathrm{H}_{2 n+2} \mathrm{O}_{1} \mathrm{SO}_{4}(\mathrm{n}>4)$, respectively. Hence, the $\mathrm{OS}$ in the homologue series 2 contained one more hydroxyl group or ether group than the corresponding one in the homologue series 1. Similarly, molecular formulas of the homologue series 3,4 , and 7 with $\mathrm{DBE}=1$ can be written as $\mathrm{C}_{n} \mathrm{H}_{2 n} \mathrm{O}_{1} \mathrm{SO}_{4}, \mathrm{C}_{n} \mathrm{H}_{2 n} \mathrm{O}_{2} \mathrm{SO}_{4}$, and $\mathrm{C}_{n} \mathrm{H}_{2 n} \mathrm{O}_{3} \mathrm{SO}_{4}$; those for series $6,9,11$, and 13 with $\mathrm{DBE}=2$ can be written as $\mathrm{C}_{n} \mathrm{H}_{2 n-2} \mathrm{O}_{2} \mathrm{SO}_{4}, \mathrm{C}_{n} \mathrm{H}_{2 n-2} \mathrm{O}_{3} \mathrm{SO}_{4}, \mathrm{C}_{n} \mathrm{H}_{2 n-2} \mathrm{O}_{4} \mathrm{SO}_{4}$, and $\mathrm{C}_{n} \mathrm{H}_{2 n-2} \mathrm{O}_{5} \mathrm{SO}_{4}$; and those for series $5,8,10,12,14$, and 15 with $\mathrm{DBE}=3$ can be written as $\mathrm{C}_{n} \mathrm{H}_{2 n-4} \mathrm{O}_{1} \mathrm{SO}_{4}$, $\mathrm{C}_{n} \mathrm{H}_{2 n-4} \mathrm{O}_{2} \mathrm{SO}_{4}, \quad \mathrm{C}_{n} \mathrm{H}_{2 n-4} \mathrm{O}_{3} \mathrm{SO}_{4}, \quad \mathrm{C}_{n} \mathrm{H}_{2 n-4} \mathrm{O}_{4} \mathrm{SO}_{4}$, $\mathrm{C}_{n} \mathrm{H}_{2 n-4} \mathrm{O}_{5} \mathrm{SO}_{4}$, and $\mathrm{C}_{n} \mathrm{H}_{2 n-4} \mathrm{O}_{6} \mathrm{SO}_{4}$, respectively. For the homologue series with $\mathrm{DBE}=2$ or 3 , the oxygen atoms other than those in the sulfate group probably belonged to hydroxyl, carbonyl, or carboxylic groups, because it is unlikely that a compound in this range of molecular weight would contain so many ether groups. CHOS with $\mathrm{DBE}=4$ or 5 represented $9.9,12.2$, and $9.5 \%$ of the total CHOS species in the WHS, NJSD + NJSN, and SHSD + SHSN samples, respectively. 


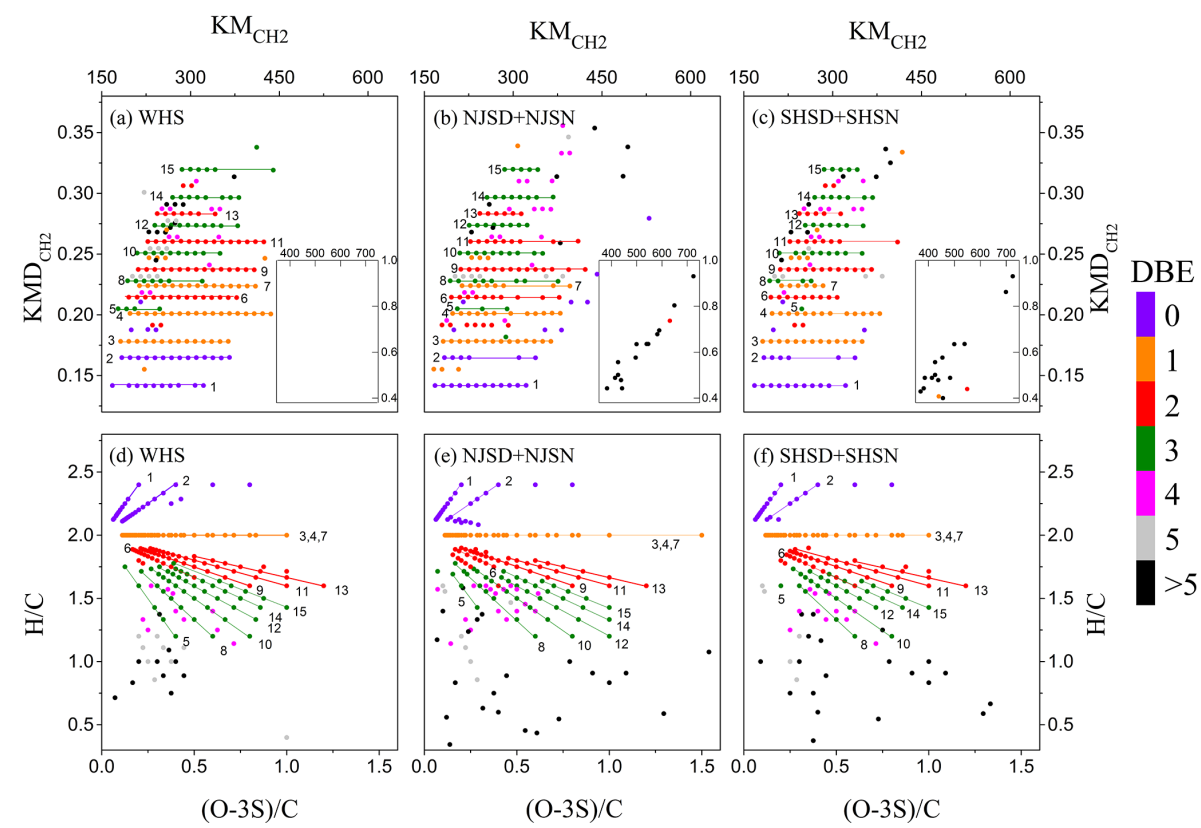

Figure 4. (a-c) $\mathrm{CH}_{2}$-Kendrick diagrams and (d-e) Van Krevelen diagrams for CHOS. The color-coding indicates the DBE values calculated from Eq. (1). The molecular formulas of the homologue series 1 to 15 can be written as $\mathrm{C}_{n} \mathrm{H}_{2 n+2} \mathrm{SO}_{4}, \mathrm{C}_{n} \mathrm{H}_{2 n+2} \mathrm{O}_{1} \mathrm{SO}_{4}$, $\mathrm{C}_{n} \mathrm{H}_{2 n} \mathrm{O}_{1} \mathrm{SO}_{4}, \mathrm{C}_{n} \mathrm{H}_{2 n} \mathrm{O}_{2} \mathrm{SO}_{4}, \mathrm{C}_{n} \mathrm{H}_{2 n-4} \mathrm{O}_{1} \mathrm{SO}_{4}, \mathrm{C}_{n} \mathrm{H}_{2 n-2} \mathrm{O}_{2} \mathrm{SO}_{4}, \mathrm{C}_{n} \mathrm{H}_{2 n} \mathrm{O}_{3} \mathrm{SO}_{4}, \mathrm{C}_{n} \mathrm{H}_{2 n-4} \mathrm{O}_{2} \mathrm{SO}_{4}, \mathrm{C}_{n} \mathrm{H}_{2 n-2} \mathrm{O}_{3} \mathrm{SO}_{4}, \mathrm{C}_{n} \mathrm{H}_{2 n-4} \mathrm{O}_{3} \mathrm{SO}_{4}$, $\mathrm{C}_{n} \mathrm{H}_{2 n-2} \mathrm{O}_{4} \mathrm{SO}_{4}, \mathrm{C}_{n} \mathrm{H}_{2 n-4} \mathrm{O}_{4} \mathrm{SO}_{4}, \mathrm{C}_{n} \mathrm{H}_{2 n-2} \mathrm{O}_{5} \mathrm{SO}_{4}, \mathrm{C}_{n} \mathrm{H}_{2 n-4} \mathrm{O}_{5} \mathrm{SO}_{4}$, and $\mathrm{C}_{n} \mathrm{H}_{2 n-4} \mathrm{O}_{6} \mathrm{SO}_{4}$, respectively ( $\left.\mathrm{n}>4\right)$.

The region of the $\mathrm{CH}_{2}$-Kendrick diagrams where $\mathrm{KM}_{\mathrm{CH}_{2}}$ is between 350 and 750 and $\mathrm{KMD}_{\mathrm{CH}_{2}}$ is larger than 0.38 appears to be of particular interest. No CHOS was observed in this region in WHS, whereas up to 6.5 and $9.5 \%$ of the total CHOS were detected there in the NJSD + NJSN and SHSD + SHSN samples, respectively. The CHOS species in this region were characterized by a high molecular weight, high degrees of unsaturation and oxidation (DBE $>5$ and $(o-3 s) / c>0.5)$, and a minimum amount of isomers (one isomer for $79 \%$ of CHOS in this region). Moreover, these $\mathrm{CHOS}$ are located in the lower right region of the VK diagrams that plot $\mathrm{H} / \mathrm{C}$ vs. $(o-3 s) / c$ ratios (Fig. 4, Wu et al., 2004; Kim et al., 2003). They are thus likely to contain one or more aromatic rings ( $\mathrm{DBE} / \mathrm{C}>0.67$, but $\mathrm{AI}<0.5)$ and come most certainly from anthropogenic precursors.

Fewer CHONS than CHOS species were observed (Fig. 5). In the $\mathrm{CH}_{2}$-Kendrick diagram, the $\mathrm{KMD}_{\mathrm{CH}_{2}}$ values of CHONS were generally larger than those of CHOS because of the presence of one or two additional nitrate group contributing to these $\mathrm{KMD}_{\mathrm{CH}_{2}}$ values. Similarly to CHOS species, CHONS species in a homologue series with identical $\mathrm{KMD}_{\mathrm{CH}_{2}}$ values form a horizontal line. Molecular formulas of the homologue series 1 and 3 with $\mathrm{DBE}=1$ can be written as $\mathrm{C}_{n} \mathrm{H}_{2 n+1} \mathrm{NO}_{3} \mathrm{SO}_{4}$ and $\mathrm{C}_{n} \mathrm{H}_{2 n+1} \mathrm{ONO}_{3} \mathrm{SO}_{4}$; those for homologue series $2,4,5$, and 8 with $\mathrm{DBE}=2$ can be written as $\mathrm{C}_{n} \mathrm{H}_{2 n-1} \mathrm{NO}_{3} \mathrm{SO}_{4}, \mathrm{C}_{n} \mathrm{H}_{2 n-1} \mathrm{ONO}_{3} \mathrm{SO}_{4}$, $\mathrm{C}_{n} \mathrm{H}_{2 n-1} \mathrm{O}_{2} \mathrm{NO}_{3} \mathrm{SO}_{4}$, and $\mathrm{C}_{n} \mathrm{H}_{2 n-1} \mathrm{O}_{3} \mathrm{NO}_{3} \mathrm{SO}_{4}$; those for series 7,9 , and 10 with $\mathrm{DBE}=3$ can be writ- ten as $\mathrm{C}_{n} \mathrm{H}_{2 n-3} \mathrm{O}_{2} \mathrm{NO}_{3} \mathrm{SO}_{4}, \mathrm{C}_{n} \mathrm{H}_{2 n-3} \mathrm{O}_{3} \mathrm{NO}_{3} \mathrm{SO}_{4}$, and $\mathrm{C}_{n} \mathrm{H}_{2 n-3} \mathrm{O}_{4} \mathrm{NO}_{3} \mathrm{SO}_{4}$; and those for series 6 with $\mathrm{DBE}=4$ can be written as $\mathrm{C}_{n} \mathrm{H}_{2 n-5} \mathrm{ONO}_{3} \mathrm{SO}_{4}(\mathrm{n}>4)$. By comparing the molecular formulas of CHOS and CHONS species, it appears that most CHONS could correspond to the addition of nitrate groups on the detected CHOS. In the VK diagrams, the homologue series 1 and 3 constitute upward lines and the other ones constitute downward lines. In the region where $\mathrm{KM}_{\mathrm{CH}_{2}}$ is between 500 and 700 and $\mathrm{KMD}_{\mathrm{CH}_{2}}$ is larger than 0.6, CHONS species with DBE values larger than 5, a high molecular weight and a high degree of oxidation $((o-3 s-2 n) / c>0.5)$ were detected in NJSD + NJSN and SHSD + SHSN, but not in WHS. According to the formulas of those CHONS species, their precursors were different from those for any CHOS species. On the other hand, a few additional CHONS species with DBE values also larger than 5, relatively low molecular weight and low degrees of saturation and oxidation $((o-3 s-2 n) / c<0.3)$ were present in the three megacities.

Figure S2 shows the numbers of CHOS and CHONS species in different mass ranges. Generally, OSs in the mass range of 250-300 Da showed the greatest variety. The number of OSs in the mass range of 200-400 Da accounted for $90.5,83.1$, and $85.4 \%$ of determined OSs in WHS, NJSD + NJSN, and SHSD + SHSN, respectively. OSs with molecular weights larger than $500 \mathrm{Da}$ characterized by high degrees of unsaturation in the KMD diagrams existed in the $\mathrm{NJ}$ and SH samples, whereas the molecular weight of all 


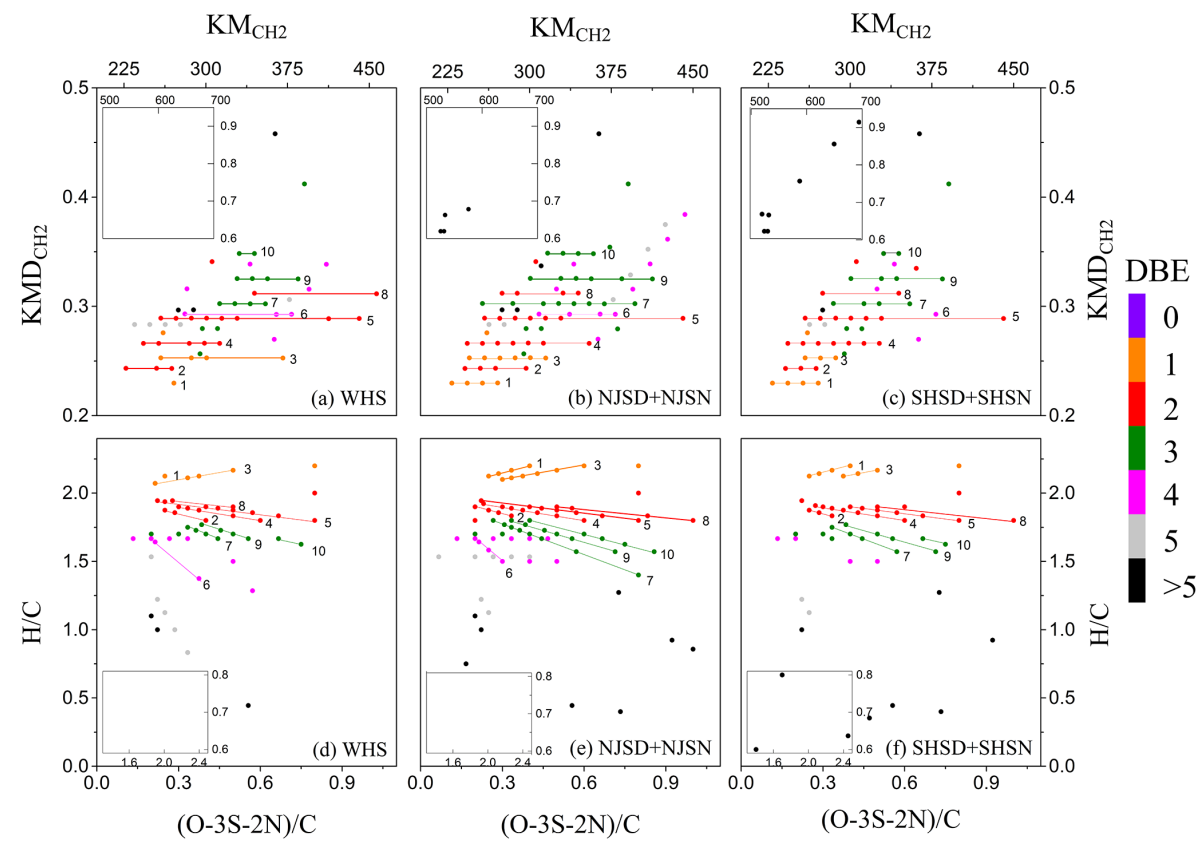

Figure 5. (a-c) $\mathrm{CH}_{2}$-Kendrick diagrams and (d-e) Van Krevelen diagrams for CHONS. The color-coding indicates the DBE values calculated from Eq. (1). The molecular formulas of the homologue series 1 to 10 can be written as $\mathrm{C}_{n} \mathrm{H}_{2 n+1} \mathrm{NO}_{3} \mathrm{SO}_{4}, \mathrm{C}_{n} \mathrm{H}_{2 n-1} \mathrm{NO}_{3} \mathrm{SO}_{4}$, $\mathrm{C}_{n} \mathrm{H}_{2 n+1} \mathrm{ONO}_{3} \mathrm{SO}_{4}, \mathrm{C}_{n} \mathrm{H}_{2 n-1} \mathrm{ONO}_{3} \mathrm{SO}_{4}, \mathrm{C}_{n} \mathrm{H}_{2 n-1} \mathrm{O}_{2} \mathrm{NO}_{3} \mathrm{SO}_{4}, \mathrm{C}_{n} \mathrm{H}_{2 n-5} \mathrm{ONO}_{3} \mathrm{SO}_{4}, \mathrm{C}_{n} \mathrm{H}_{2 n-3} \mathrm{O}_{2} \mathrm{NO}_{3} \mathrm{SO}_{4}, \mathrm{C}_{n} \mathrm{H}_{2 n-1} \mathrm{O}_{3} \mathrm{NO}_{3} \mathrm{SO}_{4}$, $\mathrm{C}_{n} \mathrm{H}_{2 n-3} \mathrm{O}_{3} \mathrm{NO}_{3} \mathrm{SO}_{4}$, and $\mathrm{C}_{n} \mathrm{H}_{2 n-3} \mathrm{O}_{4} \mathrm{NO}_{3} \mathrm{SO}_{4}$, respectively ( $>4$ ).

OSs in the WHS sample was less than $500 \mathrm{Da}$. In summary, the molecular characteristics of tentatively assigned OSs between NJSD + NJSN and SHSD + SHSN shared better similarity, probably because $\mathrm{NJ}$ and $\mathrm{SH}$ are geographically closer at the lower reach of the Yangtze River, whereas WH is at the middle reach of the Yangtze River.

\subsection{Formation pathways of isoprene-derived OSs in the three megacities}

Isoprene has been shown to be an important precursor of OSs in the three megacities. Previous studies suggest that IEPOX $\left(\mathrm{C}_{5} \mathrm{H}_{10} \mathrm{O}_{3}\right)$ and MAE $\left(\mathrm{C}_{4} \mathrm{H}_{6} \mathrm{O}_{3}\right)$ are two key reactive intermediates that are formed during isoprene oxidation under low- and high- $\mathrm{NO}_{x}$ conditions, respectively. Subsequent acid catalyzed-reactions of IEPOX and MAE in the presence of sulfates lead to the formation of $\mathrm{C}_{5} \mathrm{H}_{12} \mathrm{O}_{3} \mathrm{SO}_{4}$ and $\mathrm{C}_{4} \mathrm{H}_{8} \mathrm{O}_{3} \mathrm{SO}_{4}$, respectively (Surratt et al., 2010; Worton et al., 2013), with the $\mathrm{C}_{4}$ OS being promoted under high- $\mathrm{NO}_{x}$ conditions compared to the $\mathrm{C}_{5}$ OS. $\mathrm{C}_{5}$ and $\mathrm{C}_{4}$ OSs could also be formed from sulfate/sulfite radical-induced oxidation reactions with isoprene and its oxidation products (i.e., methyl vinyl ketone, and methacrolein) in the aqueous phase, respectively (Schone et al., 2014; Noziere et al., 2010). Since the liquid water content is not available for our ambient samples, these aqueous reaction pathways are not considered here.

In this study, the $\mathrm{S} / \mathrm{C}$ ratio has been limited to $0-0.2$ to assure that the obtained compound exists in nature (Lin et al., 2012a; Tao et al., 2014; Wozniak et al., 2008). As a result, $\mathrm{C}_{4} \mathrm{H}_{8} \mathrm{O}_{3} \mathrm{SO}_{4}$ has been eliminated by this criterion. Manually extracted ratios of the abundances of $\mathrm{C}_{4} \mathrm{H}_{8} \mathrm{O}_{3} \mathrm{SO}_{4}$ to $\mathrm{C}_{5} \mathrm{H}_{12} \mathrm{O}_{3} \mathrm{SO}_{4}$ (denoted hereafter as $\mathrm{C}_{4} / \mathrm{C}_{5}$ ratios) were used to elucidate the major formation pathway of isoprene-derived OSs in the three megacities.

In $\mathrm{SH}$ winter daytime samples, the $\mathrm{C}_{4} / \mathrm{C}_{5}$ ratio was 8.9 and decreased to 0.20 during summer. In $\mathrm{WH}$, the $\mathrm{C}_{4} / \mathrm{C}_{5}$ ratio was equal to 0.22 in winter and 0.13 in summer. In both cases, these observations are consistent with the $\mathrm{C}_{4} \mathrm{OS}$ being promoted with higher winter $\mathrm{NO}_{x}$ levels but also suggest that even in winter, isoprene OSs are formed under low- $\mathrm{NO}_{x}$ conditions. In the NJSD sample, the $\mathrm{C}_{4} / \mathrm{C}_{5}$ ratio was about 2.5 , suggesting that the high- $\mathrm{NO}_{x}$ pathway might dominate in summer in NJ (Dong et al., 2013).

\subsection{Comparison of OSs in the SH samples}

For a more accurate comparison, the abundance of $\mathrm{C}_{10} \mathrm{H}_{17} \mathrm{NO}_{3} \mathrm{SO}_{4}$ in the SHSN sample (the highest one from all the SH samples) was set arbitrarily to $100 \%$, and an abundance limit corresponding to $0.5 \%$ of this value was used to include or exclude the OSs from the four SH samples in the following comparison. Figure 6 shows that the number of OSs in the SHSD and SHSN samples was much larger than those in the SHWD and SHWN samples, respectively, consistent with a higher photochemical activity and/or higher precursor emissions in summer than in winter. The number of 


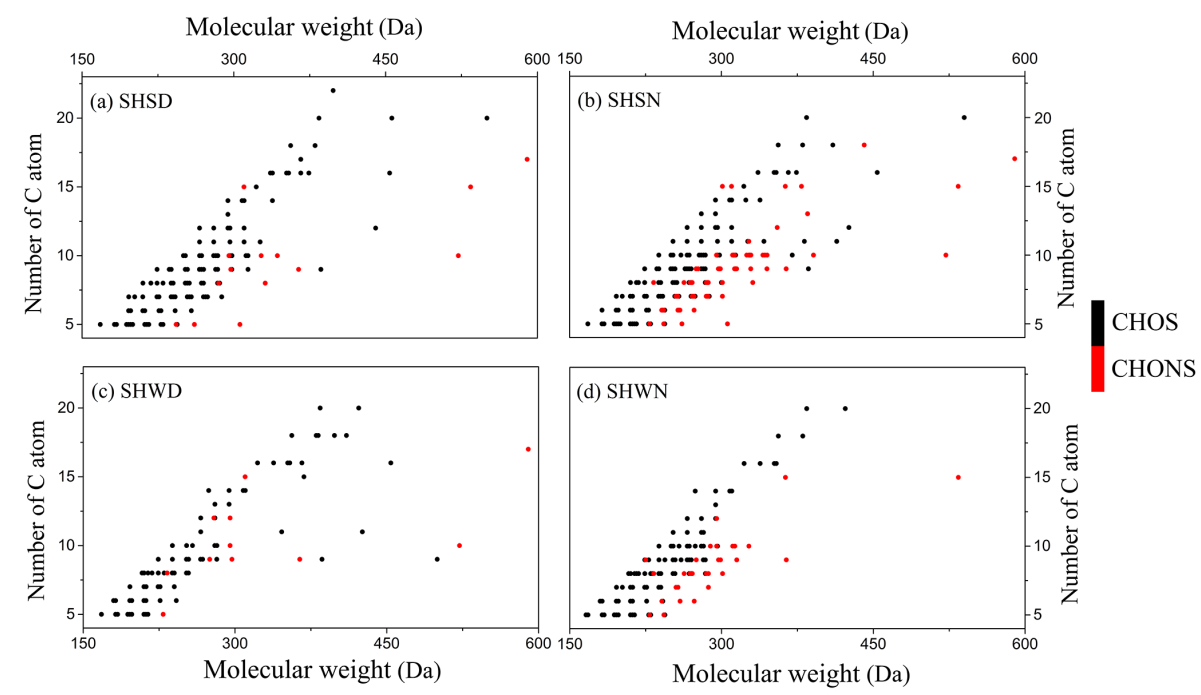

Figure 6. Number of $\mathrm{C}$ atoms of CHOS and CHONS as a function of molecular weight in the Shanghai samples. Note that only compounds with a relative abundance greater than or equal to $0.5 \%$ of that of $\mathrm{C}_{10} \mathrm{H}_{17} \mathrm{O}_{7} \mathrm{~N}_{1} \mathrm{~S}_{1}$ in the SHSN sample are shown in this figure.
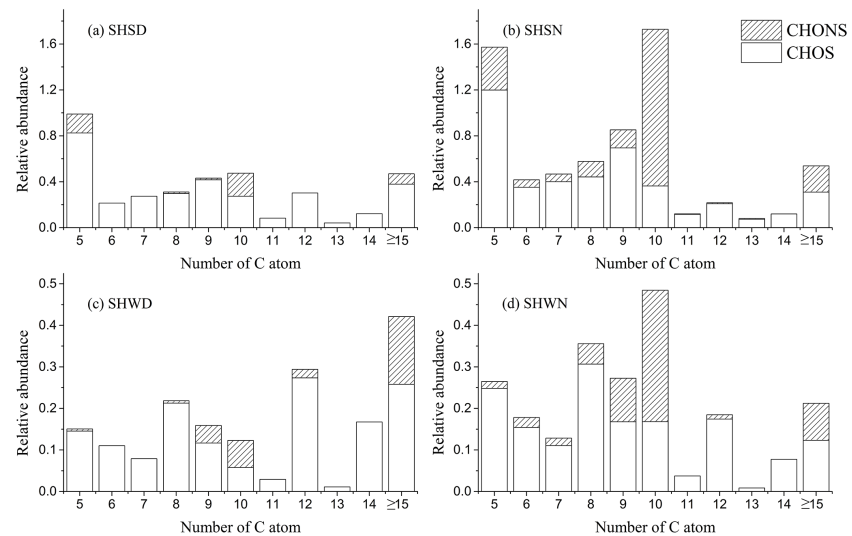

Figure 7. Relative abundance distributions of CHOS and CHONS in the Shanghai samples. Note that only compounds with a relative abundance greater than or equal to $0.5 \%$ of that of $\mathrm{C}_{10} \mathrm{H}_{17} \mathrm{O}_{7} \mathrm{~N}_{1} \mathrm{~S}_{1}$ in the SHSN sample are shown in this figure.

OSs in the SHSN and SHWN samples, especially the number of CHONS, was much larger than that in the SHSD and SHWD samples, respectively, consistent with the previous observation in Fig. 3 (see Sect. 3.2) that much more CHONS is present during nighttime.

As shown in Fig. 7, the total arbitrary abundances of OSs in the SHSD and SHSN samples were 2.1 and 3.0 times higher than in the SHWD and SHWN samples. The total arbitrary abundances of CHOS did not display significant differences between SHSD and SHSN or between SHWD and SHWN. However, the arbitrary abundances of CHONS in these SHSN and SHWN samples were 5.0 times and 2.2 times higher than in the SHSD and SHWD samples. This is consistent with an expected nighttime chemistry of $\mathrm{NO}_{3}$.
Moreover, the variety (Fig. 6) and the abundance (Fig. 7) of CHONS in both the SHWN and SHSN samples were far larger than those in SHWD and SHSD.

The fact that the SHSN sample showed a higher abundance and variety of CHONS than the SHWD sample seems to point toward a CHONS formation driven by both daytime photochemistry (and/or precursor emission) and subsequent nighttime $\mathrm{NO}_{3}$ chemistry. Similar trends of higher CHONS abundance during nighttime than during daytime were observed in Beijing, China (van Pinxteren et al., 2009), Atlanta, GA (Hatch et al., 2011), and Bakersfield, CA, USA (O'Brien et al., 2014). However, He et al. (2014) observed a reverse trend at a regional background site in the Pearl River Delta region (concentrations of nitrooxy-OSs were higher during daytime), concluding that photochemical reactions could also lead to the formation of a significant amount of nitrooxy-OSs. This photochemical pathway could contribute to the formation of the nitrooxy-OSs detected during daytime, even if they showed only relatively low abundances in this study.

Figure 7 shows the carbon number-based arbitrary abundance of CHOS and CHONS. In all four samples, more than $60 \%$ of the OSs was characterized by 5 to 10 carbon atom chains. In the SHSD and SHSN samples, $\mathrm{C}_{5}$ and $\mathrm{C}_{10}$ were the most abundant. Isoprene and monoterpenes could be the main precursors for most of the $\mathrm{C}_{5}$ and $\mathrm{C}_{10}$ OSs (Riva et al., 2015a; Surratt et al., 2008). On the other hand, a recent work (Riva et al., 2015b) suggests that a number of observed $\mathrm{C}_{10}$ OSs (e.g., $\mathrm{C}_{10} \mathrm{H}_{12} \mathrm{O}_{7} \mathrm{~S}_{1}$ ) might be derived from PAHs. In addition to $\mathrm{C}_{5}$ and $\mathrm{C}_{10}$, the relative abundances of $\mathrm{C}_{8}$, $\mathrm{C}_{9}$, and $\mathrm{C}_{14+}$ were also high in the SHWD and SHWN samples, hinting at additional precursors. In contrast, $\mathrm{C}_{10}$ derived from monoterpenes always represented the dominant cate- 
gory in spring, autumn, and winter in the Pearl River Delta, South China, and in Taiwan (Lin et al., 2012b), underlying a lesser anthropogenic influence in these two regions than in the Yangtze River region.

The VK diagrams of CHOS and CHONS in the SH samples are presented in Fig. S3, which represents a combination of Figs. 4 and 5 (with a lesser number of OSs accounted for). OSs in the four samples were characterized by similar degrees of saturation. OSs with a low degree of saturation and a high molecular weight existed in all four samples. Table 1 and Fig. S3 show that the average degree of oxidation of OSs in the SHSD and SHSN samples was higher than those in the SHWD and SHWN samples, which is consistent with a promoted photochemical activity in summer.

\section{Conclusions}

In this study, atmospheric $\mathrm{PM}_{2.5}$ samples in $\mathrm{WH}, \mathrm{NJ}$, and $\mathrm{SH}$ were analyzed using a UHPLC-Orbitrap mass spectrometer. More than 100 formulas of CHOS and dozens of formulas of CHONS with various numbers of isomers were tentatively determined in each sample. These CHOS and CHONS compounds were here tentatively regarded as organosulfates and nitrooxy-organosulfates, respectively.

Aliphatic OSs represented at least $78 \%$ of the tentatively determined OSs in the three megacity summer samples, while there were much less aromatic OSs. Comparison of the molecular formula, number of isomers, average molecular weight, and degrees of saturation and oxidation suggests that OSs in aerosol samples from $\mathrm{NJ}$ and $\mathrm{SH}$ shared more similarities.

Major OSs in these ambient samples could be derived from biogenic precursors (isoprene, monoterpenes, and sesquiterpenes), but also from PAHs. Isoprene appeared to be most likely one of the important precursors in the three megacities, and the influence of $\mathrm{NO}_{x}$ level on the nature of isoprenederived OSs is consistent with the literature. Clearly, the identity, precursors, and formation mechanisms of many OSs have yet to be positively elucidated. The systematic use of chromatographic separation prior to MS detection appears essential given the variety of the precursors and the resulting isomers.

\section{The Supplement related to this article is available online at doi:10.5194/acp-16-2285-2016-supplement.}

Acknowledgements. This study was financially supported by the National Natural Science Foundation of China (No. 21107015, 21190053, 21222703, 41575113, 21561130150), the Special Fund for PhD Studies from the Ministry of Education of China (20120071110023), and the Cyrus Tang Foundation (No. CTFFD2014001). L. Wang thanks the Newton Advanced Fellowship
(NA140106). C. George thanks the support by the European Research Council under the European Union's Seventh Framework Programme (FP/2007-2013)/ERC Grant Agreement 290852 - AIRSEA, and the Marie Curie International Research Staff Exchange project AMIS (Grant 295132).

Edited by: W. Maenhaut

\section{References}

Andreae, M. O. and Crutzen, P. J.: Atmospheric aerosols: Biogeochemical sources and role in atmospheric chemistry, Science, 276, 1052-1058, doi:10.1126/science.276.5315.1052, 1997.

Chan, M. N., Surratt, J. D., Chan, A. W. H., Schilling, K., Offenberg, J. H., Lewandowski, M., Edney, E. O., Kleindienst, T. E., Jaoui, M., Edgerton, E. S., Tanner, R. L., Shaw, S. L., Zheng, M., Knipping, E. M., and Seinfeld, J. H.: Influence of aerosol acidity on the chemical composition of secondary organic aerosol from $\beta$-caryophyllene, Atmos. Chem. Phys., 11, 1735-1751, doi:10.5194/acp-11-1735-2011, 2011.

Darer, A. I., Cole-Filipiak, N. C., O’Connor, A. E., and Elrod, M. J.: Formation and stability of atmospherically relevant isoprenederived organosulfates and organonitrates, Environ. Sci. Technol., 45, 1895-1902, doi:10.1021/es103797z, 2011.

Dong, X. Y., Gao, Y., Fu, J. S., Li, J., Huang, K., Zhuang, G. S., and Zhou, Y.: Probe into gaseous pollution and assessment of air quality benefit under sector dependent emission control strategies over megacities in Yangtze River Delta, China, Atmos. Environ., 79, 841-852, doi:10.1016/j.atmosenv.2013.07.041, 2013.

El Haddad, I., Marchand, N., D’Anna, B., Jaffrezo, J.-L., and Wortham, H.: Functional group composition of organic aerosol from combustion emissions and secondary processes at two contrasted urban environments, Atmos. Environ., 75, 308-320, doi:10.1016/j.atmosenv.2013.04.019, 2013.

Fuller, S. J., Zhao, Y. J., Cliff, S. S., Wexler, A. S., and Kalberer, M.: Direct surface analysis of time-resolved aerosol impactor samples with ultrahigh-resolution mass spectrometry, Anal. Chem., 84, 9858-9864, doi:10.1021/ac3020615, 2012.

Gomez-Gonzalez, Y., Surratt, J. D., Cuyckens, F., Szmigielski, R., Vermeylen, R., Jaoui, M., Lewandowski, M., Offenberg, J. H., Kleindienst, T. E., Edney, E. O., Blockhuys, F., Van Alsenoy, C., Maenhaut, W., and Claeys, M.: Characterization of organosulfates from the photooxidation of isoprene and unsaturated fatty acids in ambient aerosol using liquid chromatography/(-) electrospray ionization mass spectrometry, J. Mass Spectrom., 43, 371-382, doi:10.1002/jms.1329, 2008.

Guenther, A., Hewitt, C. N., Erickson, D., Fall, R., Geron, C., Graedel, T., Harley, P., Klinger, L., Lerdau, M., McKay, W. A., Pierce, T., Scholes, B., Steinbrecher, R., Tallamraju, R., Taylor, J., and Zimmerman, P.: A global-model of natural volatile organic-compound emissions, J. Geophys. Res. Atmos., 100, 8873-8892, doi:10.1029/94JD02950, 1995.

Hallquist, M., Wenger, J. C., Baltensperger, U., Rudich, Y., Simpson, D., Claeys, M., Dommen, J., Donahue, N. M., George, C., Goldstein, A. H., Hamilton, J. F., Herrmann, H., Hoffmann, T., Iinuma, Y., Jang, M., Jenkin, M. E., Jimenez, J. L., Kiendler-Scharr, A., Maenhaut, W., McFiggans, G., Mentel, Th. F., Monod, A., Prévôt, A. S. H., Seinfeld, J. H., Surratt, J. D., 
Szmigielski, R., and Wildt, J.: The formation, properties and impact of secondary organic aerosol: current and emerging issues, Atmos. Chem. Phys., 9, 5155-5236, doi:10.5194/acp-9-51552009, 2009.

Hatch, L. E., Creamean, J. M., Ault, A. P., Surratt, J. D., Chan, M. N., Seinfeld, J. H., Edgerton, E. S., Su, Y. X., and Prather, K. A.: Measurements of isoprene-derived organosulfates in ambient aerosols by aerosol time-of-flight mass spectrometry-Part 2: Temporal variability and formation mechanisms, Environ. Sci. Technol., 45, 8648-8655, doi:10.1021/es2011836, 2011.

Hawkins, L. N., Russell, L. M., Covert, D. S., Quinn, P. K., and Bates, T. S.: Carboxylic acids, sulfates, and organosulfates in processed continental organic aerosol over the southeast Pacific Ocean during VOCALS-REx 2008, J. Geophys. Res. Atmos., 115, D13201, doi:10.1029/2009JD013276, 2010.

He, Q. F., Ding, X., Wang, X. M., Yu, J. Z., Fu, X. X., Liu, T. Y., Zhang, Z., Xue, J., Chen, D. H., Zhong, L. J., and Donahue, N. M.: Organosulfates from pinene and isoprene over the Pearl River Delta, south China: Seasonal variation and implication in formation mechanisms, Environ. Sci. Technol., 48, 9236-9245, doi:10.1021/es501299v, 2014.

Hu, K. S., Darer, A. I., and Elrod, M. J.: Thermodynamics and kinetics of the hydrolysis of atmospherically relevant organonitrates and organosulfates, Atmos. Chem. Phys., 11, 8307-8320, doi:10.5194/acp-11-8307-2011, 2011.

Huang, C., Chen, C. H., Li, L., Cheng, Z., Wang, H. L., Huang, H. Y., Streets, D. G., Wang, Y. J., Zhang, G. F., and Chen, Y. R.: Emission inventory of anthropogenic air pollutants and VOC species in the Yangtze River Delta region, China, Atmos. Chem. Phys., 11, 4105-4120, doi:10.5194/acp-11-4105-2011, 2011.

Iinuma, Y., Muller, C., Berndt, T., Boge, O., Claeys, M., and Herrmann, H.: Evidence for the existence of organosulfates from beta-pinene ozonolysis in ambient secondary organic aerosol, Environ. Sci. Technol., 41, 6678-6683, doi:10.1021/es070938t, 2007a.

Iinuma, Y., Muller, C., Boge, O., Gnauk, T., and Herrmann, H.: The formation of organic sulfate esters in the limonene ozonolysis secondary organic aerosol (SOA) under acidic conditions, Atmos. Environ., 41, 5571-5583, doi:10.1016/j.atmosenv.2007.03.007, 2007b.

Kahnt, A., Behrouzi, S., Vermeylen, R., Shalamzari, M. S., Vercauteren, J., Roekens, E., Claeys, M., and Maenhaut, W.: Oneyear study of nitro-organic compounds and their relation to wood burning in $\mathrm{PM}_{10}$ aerosol from a rural site in Belgium, Atmos. Environ., 81, 561-568, doi:10.1016/j.atmosenv.2013.09.041, 2013.

Kim, S., Kramer, R. W., and Hatcher, P. G.: Graphical method for analysis of ultrahigh-resolution broadband mass spectra of natural organic matter, the van Krevelen diagram, Anal. Chem., 75, 5336-5344, doi:10.1021/ac034415p, 2003.

Koch, B. P. and Dittmar, T.: From mass to structure: An aromaticity index for high-resolution mass data of natural organic matter, Rapid Commun. Mass Sp., 20, 926-932, doi:10.1002/rcm.2386, 2006.

Kristensen, K. and Glasius, M.: Organosulfates and oxidation products from biogenic hydrocarbons in fine aerosols from a forest in North West Europe during spring, Atmos. Environ., 45, 45464556, doi:10.1016/j.atmosenv.2011.05.063, 2011.

Kundu, S., Quraishi, T. A., Yu, G., Suarez, C., Keutsch, F. N., and Stone, E. A.: Evidence and quantitation of aromatic organosul- fates in ambient aerosols in Lahore, Pakistan, Atmos. Chem. Phys., 13, 4865-4875, doi:10.5194/acp-13-4865-2013, 2013.

Liggio, J., Li, S. M., and McLaren, R.: Heterogeneous reactions of glyoxal on particulate matter: Identification of acetals and sulfate esters, Environ. Sci. Technol., 39, 1532-1541, doi:10.1021/es048375y, 2005.

Lin, P., Rincon, A. G., Kalberer, M., and Yu, J. Z.: Elemental composition of HULIS in the Pearl River Delta region, China: Results inferred from positive and negative electrospray high resolution mass spectrometric data, Environ. Sci. Technol., 46, 7454-7462, doi:10.1021/es300285d, 2012a.

Lin, P., Yu, J. Z., Engling, G., and Kalberer, M.: Organosulfates in humic-like substance fraction isolated from aerosols at seven locations in East Asia: A study by ultra-high-resolution mass spectrometry, Environ. Sci. Technol., 46, 13118-13127, doi:10.1021/es303570v, 2012b.

Lin, Y. H., Zhang, Z., Docherty, K. S., Zhang, H., Budisulistiorini, S. H., Rubitschun, C. L., Shaw, S. L., Knipping, E. M., Edgerton, E. S., Kleindienst, T. E., Gold, A., and Surratt, J. D.: Isoprene epoxydiols as precursors to secondary organic aerosol formation: acid-catalyzed reactive uptake studies with authentic compounds, Environ. Sci. Technol., 46, 250-258, doi:10.1021/es202554c, 2012c.

Lin, Y. H., Zhang, H. F., Pye, H. O. T., Zhang, Z. F., Marth, W. J., Park, S., Arashiro, M., Cui, T. Q., Budisulistiorini, H., Sexton, K. G., Vizuete, W., Xie, Y., Luecken, D. J., Piletic, I. R., Edney, E. O., Bartolotti, L. J., Gold, A., and Surratt, J. D.: Epoxide as a precursor to secondary organic aerosol formation from isoprene photooxidation in the presence of nitrogen oxides, P. Natl. Acad. Sci. USA, 110, 6718-6723, doi:10.1073/pnas.1221150110, 2013.

Ma, Y., Chen, J. M., and Wang, L.: Characteristics and formation mechanisms of atmospheric organosulfates, Prog. Chem., 24, 2277-2286, 2012.

Ma, Y., Xu, X. K., Song, W. H., Geng, F. H., and Wang, L.: Seasonal and diurnal variations of particulate organosulfates in urban Shanghai, China, Atmos. Environ., 85, 152-160, doi:10.1016/j.atmosenv.2013.12.017, 2014.

Magari, S. R., Schwartz, J., Williams, P. L., Hauser, R., Smith, T. J., and Christiani, D. C.: The association of particulate air metal concentrations with heart rate variability, Environ. Health Perspect., 110, 875-880, 2002.

Noziere, B., Ekstrom, S., Alsberg, T., and Holmstrom, S.: Radical-initiated formation of organosulfates and surfactants in atmospheric aerosols, Geophys. Res. Lett., 37, L05806, doi:10.1029/2009GL041683, 2010.

O’Brien, R. E., Laskin, A., Laskin, J., Rubitschun, C. L., Surratt, J. D., and Goldstein, A. H.: Molecular characterization of S- and Ncontaining organic constituents in ambient aerosols by negative ion mode high-resolution nanospray desorption electrospray ionization mass spectrometry: CalNex 2010 field study, J. Geophys. Res. Atmos., 119, 12706-12720, doi:10.1002/2014JD021955, 2014.

Olson, C. N., Galloway, M. M., Yu, G., Hedman, C. J., Lockett, M. R., Yoon, T., Stone, E. A., Smith, L. M., and Keutsch, F. N.: Hydroxycarboxylic acid-derived organosulfates: synthesis, stability, and quantification in ambient aerosol, Environ. Sci. Technol., 45, 6468-6474, doi:10.1021/es201039p, 2011. 
Ostro, B., Feng, W. Y., Broadwin, R., Green, S., and Lipsett, M.: The effects of components of fine particulate air pollution on mortality in California: Results from CALFINE, Environ. Health Perspect., 115, 13-19, doi:10.1289/ehp.9281, 2007.

Paulot, F., Crounse, J. D., Kjaergaard, H. G., Kurten, A., St Clair, J. M., Seinfeld, J. H., and Wennberg, P. O.: Unexpected epoxide formation in the gas-phase photooxidation of isoprene, Science, 325, 730-733, doi:10.1126/science.1172910, 2009.

Riva, M., Budisulistiorini, S. H., Zhang, Z., Gold, A., and Surratt, J. D.: Chemical characterization of secondary organic aerosol constituents from isoprene ozonolysis in the presence of acidic aerosol, Atmos. Environ., doi:10.1016/j.atmosenv.2015.06.027, in press, 2015a.

Riva, M., Tomaz, S., Cui, T., Lin, Y.-H., Perraudin, E., Gold, A., Stone, E. A., Villenave, E., and Surratt, J. D.: Evidence for an unrecognized secondary anthropogenic source of organosulfates and sulfonates: Gas-phase oxidation of polycyclic aromatic hydrocarbons in the presence of sulfate aerosol, Environ. Sci. Technol., 49, 6654-6664, doi:10.1021/acs.est.5b00836, 2015 b.

Rudzinski, K. J., Gmachowski, L., and Kuznietsova, I.: Reactions of isoprene and sulphoxy radical-anions - a possible source of atmospheric organosulphites and organosulphates, Atmos. Chem. Phys., 9, 2129-2140, doi:10.5194/acp-9-2129-2009, 2009.

Schindelka, J., Iinuma, Y., Hoffmann, D., and Herrmann, H.: Sulfate radical-initiated formation of isoprene-derived organosulfates in atmospheric aerosols, Faraday Discuss., 165, 237-259, doi:10.1039/c3fd00042g, 2013.

Schone, L., Schindelka, J., Szeremeta, E., Schaefer, T., Hoffmann, D., Rudzinski, K. J., Szmigielski, R., and Herrmann, H.: Atmospheric aqueous phase radical chemistry of the isoprene oxidation products methacrolein, methyl vinyl ketone, methacrylic acid and acrylic acid-kinetics and product studies, Phys. Chem. Chem. Phys., 16, 6257-6272, doi:10.1039/c3cp54859g, 2014.

Shalamzari, M. S., Kahnt, A., Vermeylen, R., Kleindienst, T. E., Lewandowski, M., Cuyckens, F., Maenhaut, W., and Claeys, M.: Characterization of polar organosulfates in secondary organic aerosol from the green leaf volatile 3-Z-hexenal, Environ. Sci. Technol., 48, 12671-12678, doi:10.1021/es503226b, 2014.

Staudt, S., Kundu, S., Lehmler, H. J., He, X. R., Cui, T. Q., Lin, Y. H., Kristensen, K., Glasius, M., Zhang, X. L., Weber, R. J., Surratt, J. D., and Stone, E. A.: Aromatic organosulfates in atmospheric aerosols: Synthesis, characterization, and abundance, Atmos. Environ., 94, 366-373, doi:10.1016/j.atmosenv.2014.05.049, 2014.

Stone, E. A., Hedman, C. J., Sheesley, R. J., Shafer, M. M., and Schauer, J. J.: Investigating the chemical nature of humic-like substances (HULIS) in North American atmospheric aerosols by liquid chromatography tandem mass spectrometry, Atmos. Environ., 43, 4205-4213, doi:10.1016/j.atmosenv.2009.05.030, 2009.

Surratt, J. D., Kroll, J. H., Kleindienst, T. E., Edney, E. O., Claeys, M., Sorooshian, A., Ng, N. L., Offenberg, J. H., Lewandowski, M., Jaoui, M., Flagan, R. C., and Seinfeld, J. H.: Evidence for organosulfates in secondary organic aerosol, Environ. Sci. Technol., 41, 517-527, doi:10.1021/es062081q, 2007.

Surratt, J. D., Gomez-Gonzalez, Y., Chan, A. W. H., Vermeylen, R., Shahgholi, M., Kleindienst, T. E., Edney, E. O., Offenberg, J. H., Lewandowski, M., Jaoui, M., Maenhaut, W., Claeys, M., Flagan, R. C., and Seinfeld, J. H.: Organosulfate formation in biogenic secondary organic aerosol, J. Phys. Chem. A, 112, 8345-8378, doi:10.1021/jp802310p, 2008.

Surratt, J. D., Chan, A. W. H., Eddingsaas, N. C., Chan, M. N., Loza, C. L., Kwan, A. J., Hersey, S. P., Flagan, R. C., Wennberg, P. O., and Seinfeld, J. H.: Reactive intermediates revealed in secondary organic aerosol formation from isoprene, P. Natl. Acad. Sci. USA, 107, 6640-6645, doi:10.1073/pnas.0911114107, 2010.

Szmigielski, R.: Evidence for $\mathrm{C}_{5}$ organosulfur secondary organic aerosol components from in-cloud processing of isoprene: Role of reactive $\mathrm{SO}_{4}$ and $\mathrm{SO}_{3}$ radicals, Atmos. Environ. doi:10.1016/j.atmosenv.2015.10.072, in press, 2015.

Tao, S., Lu, X., Levac, N., Bateman, A. P., Nguyen, T. B., Bones, D. L., Nizkorodov, S. A., Laskin, J., Laskin, A., and Yang, X.: Molecular characterization of organosulfates in organic aerosols from Shanghai and Los Angeles urban areas by nanospray-desorption electrospray ionization high-resolution mass spectrometry, Environ. Sci. Technol., 48, 10993-11001, doi:10.1021/es5024674, 2014.

Tolocka, M. P. and Turpin, B.: Contribution of organosulfur compounds to organic aerosol mass, Environ. Sci. Technol., 46, 7978-7983, doi:10.1021/es300651v, 2012.

van Pinxteren, D., Bruggemann, E., Gnauk, T., Iinuma, Y., Muller, K., Nowak, A., Achtert, P., Wiedensohler, A., and Herrmann, H.: Size- and time-resolved chemical particle characterization during CAREBeijing-2006: Different pollution regimes and diurnal profiles, J. Geophys. Res. Atmos., 114, D00g09, doi:10.1029/2008JD010890, 2009.

Wang, L., Du, H. H., Chen, J. M., Zhang, M., Huang, X. Y., Tan, H. B., Kong, L. D., and Geng, F. H.: Consecutive transport of anthropogenic air masses and dust storm plume: Two case events at Shanghai, China, Atmos. Res., 127, 22-33, doi:10.1016/j.atmosres.2013.02.011, 2013.

Worton, D. R., Surratt, J. D., LaFranchi, B. W., Chan, A. W. H., Zhao, Y. L., Weber, R. J., Park, J. H., Gilman, J. B., de Gouw, J., Park, C., Schade, G., Beaver, M., St Clair, J. M., Crounse, J., Wennberg, P., Wolfe, G. M., Harrold, S., Thornton, J. A., Farmer, D. K., Docherty, K. S., Cubison, M. J., Jimenez, J. L., Frossard, A. A., Russell, L. M., Kristensen, K., Glasius, M., Mao, J. Q., Ren, X. R., Brune, W., Browne, E. C., Pusede, S. E., Cohen, R. C., Seinfeld, J. H., and Goldstein, A. H.: Observational insights into aerosol formation from isoprene, Environ. Sci. Technol., 47, 11403-11413, doi:10.1021/es4011064, 2013.

Wozniak, A. S., Bauer, J. E., Sleighter, R. L., Dickhut, R. M., and Hatcher, P. G.: Technical Note: Molecular characterization of aerosol-derived water soluble organic carbon using ultrahigh resolution electrospray ionization Fourier transform ion cyclotron resonance mass spectrometry, Atmos. Chem. Phys., 8, 50995111, doi:10.5194/acp-8-5099-2008, 2008.

Wu, Z. G., Rodgers, R. P., and Marshall, A. G.: Two- and three-dimensional van Krevelen diagrams: A graphical analysis complementary to the Kendrick mass plot for sorting elemental compositions of complex organic mixtures based on ultrahigh-resolution broadband Fourier transform ion cyclotron resonance mass measurements, Anal. Chem., 76, 2511-2516, doi:10.1021/ac0355449, 2004.

Xiao, S., Wang, M. Y., Yao, L., Kulmala, M., Zhou, B., Yang, X., Chen, J. M., Wang, D. F., Fu, Q. Y., Worsnop, D. R., and Wang, L.: Strong atmospheric new particle formation in winter 
in urban Shanghai, China, Atmos. Chem. Phys., 15, 1769-1781, doi:10.5194/acp-15-1769-2015, 2015.

Zhang, H. F., Worton, D. R., Lewandowski, M., Ortega, J., Rubitschun, C. L., Park, J. H., Kristensen, K., Campuzano-Jost, P., Day, D. A., Jimenez, J. L., Jaoui, M., Offenberg, J. H., Kleindienst, T. E., Gilman, J., Kuster, W. C., de Gouw, J., Park, C., Schade, G. W., Frossard, A. A., Russell, L., Kaser, L., Jud, W., Hansel, A., Cappellin, L., Karl, T., Glasius, M., Guenther, A., Goldstein, A. H., Seinfeld, J. H., Gold, A., Kamens, R. M., and Surratt, J. D.: Organosulfates as tracers for secondary organic aerosol (SOA) formation from 2-Methyl-3-Buten-2-ol (MBO) in the atmosphere, Environ. Sci. Technol., 46, 94379446, doi:10.1021/es301648z, 2012.
Zheng, J., Ma, Y., Chen, M. D., Zhang, Q., Wang, L., Khalizov, A. F., Yao, L., Wang, Z., Wang, X., and Chen, L. X.: Measurement of atmospheric amines and ammonia using the high resolution time-of-flight chemical ionization mass spectrometry, Atmos. Environ., 102, 249-259, doi:10.1016/j.atmosenv.2014.12.002, 2015. 